Annales Geophysicae (2003) 21: 955-982 (C) European Geosciences Union 2003

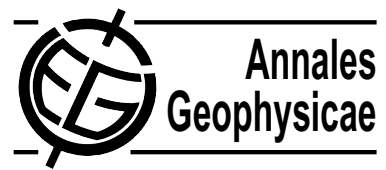

\title{
IMF control of cusp proton emission intensity and dayside convection: implications for component and anti-parallel reconnection
}

\author{
M. Lockwood ${ }^{1,2}$, B. S. Lanchester ${ }^{1}$, H. U. Frey ${ }^{3}$, K. Throp ${ }^{1}$, S. K. Morley ${ }^{1}$, S. E. Milan ${ }^{4}$, and M. Lester ${ }^{4}$ \\ ${ }^{1}$ Department of Physics and Astronomy, Southampton University, Southampton, Hampshire, UK \\ 2 also at Rutherford Appleton Laboratory, Chilton, Oxfordshire, UK \\ ${ }^{3}$ Space Sciences Laboratory, University of California, Berkeley, CA., USA \\ ${ }^{4}$ Department of Physics and Astronomy, Leicester University, Leicester, UK
}

Received: 12 July 2002 - Revised: 30 September 2002 - Accepted: 15 October 2002

\begin{abstract}
We study a brightening of the Lyman- $\alpha$ emission in the cusp which occurred in response to a short-lived southward turning of the interplanetary magnetic field (IMF) during a period of strongly enhanced solar wind plasma concentration. The cusp proton emission is detected using the SI-12 channel of the FUV imager on the IMAGE spacecraft. Analysis of the IMF observations recorded by the ACE and Wind spacecraft reveals that the assumption of a constant propagation lag from the upstream spacecraft to the Earth is not adequate for these high time-resolution studies. The variations of the southward IMF component observed by ACE and Wind allow for the calculation of the ACE-to-Earth lag as a function of time. Application of the derived propagation delays reveals that the intensity of the cusp emission varied systematically with the IMF clock angle, the relationship being particularly striking when the intensity is normalised to allow for the variation in the upstream solar wind proton concentration. The latitude of the cusp migrated equatorward while the lagged IMF pointed southward, confirming the lag calculation and indicating ongoing magnetopause reconnection. Dayside convection, as monitored by the SuperDARN network of radars, responded rapidly to the IMF changes but lagged behind the cusp proton emission response: this is shown to be as predicted by the model of flow excitation by Cowley and Lockwood (1992). We use the numerical cusp ion precipitation model of Lockwood and Davis (1996), along with modelled Lyman- $\alpha$ emission efficiency and the SI-12 instrument response, to investigate the effect of the sheath field clock angle on the acceleration of ions on crossing the dayside magnetopause. This modelling reveals that the emission commences on each reconnected field line 2-2.5 min after it is opened and peaks $3-5 \mathrm{~min}$ after it is opened. We discuss how comparison of the Lyman- $\alpha$ intensities with oxygen emissions observed simultaneously by the SI-13 channel of the FUV instrument offers an opportunity to test whether or not the clock angle dependence is consistent with the "component" or the "anti-parallel" reconnection
\end{abstract}

Correspondence to: M. Lockwood (M.Lockwood@rl.ac.uk) hypothesis.

Key words. Magnetospheric physics (magnetopause, cusp and boundary layers; solar wind-magnetosphere interactions) - Space plasma physics (magnetic reconnection)

\section{Introduction}

Since it was first postulated by Dungey $(1953,1961)$ as an explanation of the circulation of magnetic flux and plasma in the outer magnetosphere and the high-latitude ionosphere, the phenomenon of magnetic reconnection has been uniquely successful in explaining the dominant features of the transfer of mass, energy and momentum from the solar wind into the magnetosphere across its outer boundary, the magnetopause. Reconnection of the geomagnetic field with southwardpointing draped interplanetary magnetic field (IMF) in the magnetosheath takes place at "low latitudes" (meaning, between the magnetic cusps, such that the reconnection is with closed magnetospheric field lines which directly connect the ionospheres in opposite hemispheres). This generates open flux (which connects the magnetosphere to interplanetary space by threading the magnetopause). On the other hand, for northward IMF the reconnection is at higher latitudes (antisunward of one or both cusps) and is most likely to be with pre-existing open flux, produced during a prior period of southward IMF. Studies have shown that the total voltage placed across the magnetosphere by reconnection varies with the northward component of the IMF in the Geocentric Solar Magnetospheric (GSM) frame $\left[B_{z}\right]_{\mathrm{GSM}}$ and thus, for a constant IMF magnitude, with the IMF clock angle $\theta_{\mathrm{IMF}}=\tan ^{-1}\left\{\left|B_{y}\right|_{\mathrm{GSM}} /\left[B_{z}\right]_{\mathrm{GSM}}\right\}$ (Reiff et al., 1981; Doyle and Burke, 1983; Cowley, 1984a; b; Reiff and Luhmann, 1986; Etemadi et al., 1988; Boyle et al., 1997). This is also reflected in the associated ionospheric current systems (Nishida, 1968a, b; Friis-Christensen et al., 1985; Ahn et al., 1992). For southward IMF $\left(\left[B_{z}\right]_{\mathrm{GSM}}<0\right)$, the reconnection voltage is the rate of production of open flux (typically, $80 \mathrm{kV}$ 
$\left.=8 \times 10^{4} \mathrm{Wbs}^{-1}\right)$. This open flux is subsequently swept into the geomagnetic tail by the solar wind flow in the growth phase of substorms. Thus, the substorm phenomenon, and geomagnetic activity in general, is also critically dependent on the IMF $\left[B_{z}\right]_{\mathrm{GSM}}$ component and the IMF clock angle (Schatten and Wilcox, 1967; Arnoldy, 1971; Davis et al., 1997). For northward IMF, the reconnection voltage is the rate at which flux is reconfigured at the lobe magnetopause, but there may also be some voltage associated with any open flux generation that is still taking place. Note that, unlike the reconnection with closed field lines that dominates for southward IMF, lobe reconnection with open field lines does not have to be the same, in terms of either voltage or location, in the Northern and Southern Hemispheres.

\subsection{Component and anti-parallel reconnection}

A key unresolved question of magnetospheric physics is why the reconnection voltage depends on the IMF clock angle in the manner that is observed (e.g. Fedder et al., 1991). The draped IMF in the magnetosheath reconnects with the magnetospheric field, and the orientation of this magnetosheath field for a given IMF clock angle $\theta_{\mathrm{IMF}}$ is a complicated function of position on the magnetopause (Kobel and Flückiger, 1994). However, broadly speaking, the IMF clock angle $\theta_{\text {IMF }}$ is conserved across the subsolar bow shock (because here it is the $X$-component of the flow and the field which is altered by the bow shock) and it is the flow streamlines from this subsolar region which coat most of the magnetopause boundary. Comparisons of magnetic field observations made by spacecraft in the magnetosheath and in the undisturbed solar wind show that the appropriately lagged sheath field clock angle, close to the magnetopause, is very similar to the upstream IMF clock angle in the same frame, $\theta_{\mathrm{IMF}}$ (e.g. Opgenoorth et al., 2001). However for a given $\theta_{\mathrm{IMF}}$, the clock angle of the sheath field with respect to the local interior field, $\theta_{\mathrm{sh}}$, is a function of position on the magnetopause, because the orientation of the interior field in the GSM frame varies with location (Luhmann et al., 1984).

Two main types of behaviour have been postulated to describe the variation of reconnection voltage with the IMF clock angle $\theta_{\text {IMF. }}$ These are called the "component" and the "anti-parallel" hypotheses. For component reconnection (Sonnerup, 1974; Gonzales and Mozer, 1974), the reconnection site is thought of as not moving to any great extent with variations in $\theta_{\mathrm{IMF}}$ : rather it remains relatively close to the subsolar region where the magnetosheath flow is slow and the static plasma pressure is high. In this case, the component of the sheath field that is normal to the interior field at the reconnection X-line has no effect on the reconnection itself, and only the component anti-parallel to the interior field has any relevance, with the reconnection rate for a given sheath field magnitude therefore depending on the clock angle. (Only after reconnection does the component perpendicular to the interior field have a significant effect in that it determines the evolution of the newly-reconnected field lines away from the $\mathrm{X}$-line under the influence of the magnetic curvature force.) Thus, for component reconnection, $\theta_{\mathrm{IMF}}$ determines $\theta_{\mathrm{sh}}$ at the reconnection X-line which, in turn, modulates the reconnection voltage, either by changing the reconnection rate or the length of the X-line (or both).

The anti-parallel hypothesis, on the other hand, is that changes in $\theta_{\mathrm{IMF}}$ cause the reconnection site to move over the magnetopause, such that the clock angle with respect to the interior field $\theta_{\mathrm{sh}}$ is always close to $180^{\circ}$, i.e. the interior and the exterior (sheath) fields remain anti-parallel at the reconnection site (Crooker, 1979). In this scenario, it is the conditions at the reconnection site(s) that control the reconnection rate and the length of the active reconnection X-line(s), and these both modulate the reconnection voltage.

The two hypotheses predict the same reconnection sites, behaviour and voltage for purely southward $\left(\theta_{\mathrm{IMF}}=\pi\right)$ and purely northward $\left(\theta_{\mathrm{IMF}}=0\right) \mathrm{IMF}$ orientations. The differences occur for intermediate clock angles. An indication of the general behaviour comes from studies of the cusp/cleft aurora (dominated by $630 \mathrm{~nm}$ emissions caused by magnetosheath-like electron precipitation down newlyopened field lines), as a function of the IMF clock angle $\theta_{\mathrm{IMF}}$ (Sandholt et al., 1998; Lockwood and Moen, 1999; McCrea et al., 2000). For southward IMF $\left(B_{z}<0, \theta_{\mathrm{IMF}}>\pi / 2\right)$, a single, relatively low-latitude band of cusp/cleft aurora is observed, consistent with low-latitude reconnection. For strongly northward IMF $\left(B_{z}>0, \theta_{\mathrm{IMF}}\right.$ less than roughly $\pi / 4)$, a single band of cusp/cleft aurora is seen at higher latitudes, consistent with lobe reconnection. If the IMF rotates slowly through intermediate clock angles $\left(B_{z}>0, \pi / 4<\right.$ $\theta_{\mathrm{IMF}}<\pi / 2$ ), both bands of aurora co-exist with an evolution from one to the other. This implies anti-parallel reconnection for the lobe X-line but there is a debate concerning the lower-latitude reconnection that generates the lowerlatitude band of cusp/cleft aurora by opening closed geomagnetic field lines.

For the component hypothesis, the reconnection X-line will remain close to the same, low-latitude location as $\theta_{\mathrm{IMF}}$ decreases to around $\pi / 2$ : there may be a range of clock angles at which this low-latitude X-line can co-exist with lobe reconnection, but as $\theta_{\mathrm{IMF}}$ approaches zero the reconnection will only be found at lobe site(s), antisunward of the cusp(s). On the other hand, the anti-parallel paradigm predicts that the $\mathrm{X}$-line will bifurcate as $\theta_{\mathrm{IMF}}$ decreases from its peak value of $\pi$, the two halves migrating into the pre-noon and post-noon sectors and to higher latitudes as a continuous function of $\theta_{\mathrm{IMF}}$ (Luhmann et al., 1984). A key difference between the two hypotheses is that near the reconnection site(s) the clock angle $\theta_{\mathrm{sh}}$ across the magnetopause, between the sheath field and the magnetospheric field, is always close to $\pi$ for antiparallel reconnection but varies between $\pi$ and $\pi / 2$, or even smaller, for component reconnection.

There is evidence in favour of both hypotheses; however, none of that evidence is conclusive - raising the possibility that magnetopause reconnection has elements of both. The accelerated flows seen on the magnetopause are broadly consistent with the component hypotheses because the reconnected field lines are seen emanating from reconnection sites 
that appear to remain at relatively low latitudes (Gosling et al., 1990a; Scurry et al., 1994; Kim et al., 2002). Other reconnection signatures, such as Flux Transfer Events (FTEs) are also consistent with low-latitude reconnection sites at all clock angles greater than about $\pi / 2$ (Berchem and Russell, 1984; Daly et al., 1984; Rijnbeek et al., 1984; Russell et al., 1985; Kawano and Russell, 1996; 1997). On the other hand, observations from a pair of spacecraft close to the magnetopause have been interpreted in terms of anti-parallel reconnection by Šafránková et al. (1998). However, much of the evidence for anti-parallel magnetopause reconnection comes from signatures seen in the dayside cusp ionosphere. For the bifurcation of the X-line predicted by Luhmann et al. (1984), Coleman et al. (2000) point out the ionospheric merging gap will bifurcate and Lockwood and Moen (1999) presented examples of $630 \mathrm{~nm}$ red-line cusp images which they interpreted in terms of such a bifurcating merging gap. Coleman et al. (2001) predict that for IMF $B_{z}<0$, and $\left|B_{y}\right|=\left|B_{z}\right|$, the ionospheric flow would be equatorward at noon and poleward at two active merging gaps on either side of noon, and they present examples of such a flow configuration in SuperDARN radar data. However, such a flow configuration was also predicted by Lockwood (1994) as a signature of transient reconnection in which the active reconnection X-line bifurcated, such that the active segments moved away from noon towards dawn and dusk, but remained at low latitudes. Examples consistent with such transient events have been presented by Lockwood et al. (1993), Milan et al. (2000a) and McWilliams et al. (2001). With this in mind, the observations by Chisham et al. (2002) are important because they present an example consistent with a bifurcated $\mathrm{X}$-line which remains stable while the IMF orientation is stable: thus, this indeed appears to be different from the travelling active Xlines in transient reconnection pulses inferred by Lockwood et al. (1993). The difficulty with using ionospheric signatures is that many of the arguments rely, explicitly or implicitly, on field line mapping using a model of the magnetospheric field. Such field models do not have an adequate representation of the magnetopause and its boundary layers. There are very large uncertainties in the mapping of field lines near the magnetopause because the models do not allow for the amount of open flux threading the magnetopause, nor do they allow for how it is spatially distributed: both of these factors have a considerable effect on how a reconnection X-line maps to the ionospheric merging gap (Crooker et al., 1991).

\subsection{Proton precipitation in the cusp region}

The theory of the cusp ion precipitation produced by magnetic reconnection has been reviewed by Lockwood (1995). Numerical modelling based on this theory has been very successful in reproducing the cusp proton signatures (Onsager et al., 1993; Lockwood and Davis, 1996; Lockwood, 1997b; Lockwood et al., 1998). These theoretical ideas, and the numerical models based on them, contain a number of elements. They allow for variations in the plasma concentration, temperature and flow with position in the mag- netosheath: fully-consistent predictions of these parameters are only available from global MHD models and, in practice, gas-dynamic predictions (which neglect the sheath field) have been used (Spreiter et al., 1966). The evolution of each newly-reconnected field line in this sheath flow is computed from the balance of stresses tangential to the magnetopause: in effect, the Whalén relation is used to determine the field line motion that causes the plasma to flow into the main magnetopause rotational discontinuity at the local Alfvén speed in the de-Hoffman Teller frame of reference (Cowley and Owen, 1989; Cooling et al., 2001). The model also allows for the acceleration of the protons on crossing the magnetopause rotational discontinuity by flowing along the newlyopened field line (Hill and Reiff, 1977), the distribution functions of the injected protons being computed using the theory of Cowley (1982). This theory has been very successful in explaining the ion distribution functions on both sides of the magnetopause, especially for southward IMF (Smith and Rodgers, 1991; Gosling et al., 1990b; Fuselier et al., 1991; Fedorov et al., 1999). Lockwood and Davis (1996) and Lockwood (1997) used this theory but predicted ion energies that were somewhat too high, compared with typical cusp observations. The present paper shows that the IMF clock angle and the direction of evolution of the newly-opened flux provides an explanation for this discrepancy. An additional element that can be introduced into the cusp ion model is ion acceleration at an interior $\mathrm{RD}$, standing in the inflow to the open magnetopause from the magnetospheric side of the boundary (Lockwood et al., 1996). This can generate more energetic ions on the equatorward edge of the cusp, consistent with observations (Kremser et al., 1995; Lockwood and Moen, 1996; Lockwood, 1997a; b). The last element of the models is to allow for the time-of-flight of ions from every source point on the open magnetopause to the ionosphere. The motion is assumed to be adiabatic and scatter-free such that Liouville's theorem and conservation of energy can be applied. The pitch angle evolves with the field strength (Burch et al., 1982) which, like the field-aligned distance, is taken from an empirical magnetic field model. Allowance for these timeof-flight effects with an open magnetopause can explain the "bowl" and "V-shaped" spin angle distributions observed for precipitating cusp protons (Lockwood, 1997b).

It should be noted that for low reconnection rates, the use of gas-dynamic predictions may be inadequate. The lack of fast subsolar reconnection can result in a strong draped sheath field at the nose of the magnetosphere, and the increased magnetic pressure produces a "plasma depletion layer" (PDL). If a PDL is present, the sheath densities within it are reduced and the ion temperature becomes anisotropic. Both these changes to the sheath ion population close to the magnetopause could, potentially, influence the cusp ion precipitation spectrum.

\subsection{Proton aurora in the cusp}

In this paper, we make use of the Lyman- $\alpha$ emission seen in the cusp region. This is produced by the precipitation of 
solar wind protons into the cusp along newly-opened field lines. We use observations by the FUV instrument on the IMAGE spacecraft, which requires relatively high solar wind densities before the cusp Lyman- $\alpha$ emission can be detected.

Auroral emissions are generally excited by both electron and proton precipitation. Electron capture of precipitating protons can yield excited neutral hydrogen which emit several lines, including Lyman- $\alpha$, on return to a lower energy state (Eather, 1967). These emissions are Doppler shifted if viewed in a fixed frame. They have been observed in the cusp using groundbased instruments (Lorentzen and Moen, 2000; Moen et al., 1998) and the SI-12/FUV imager on the IMAGE satellite (Frey et al., 2002). The SI-12 instrument is most sensitive to the Doppler shifted emission around $121.82 \mathrm{~nm}$. The passband has a minimum response at the non-shifted line at $121.57 \mathrm{~nm}$ which removes the unshifted geocoronal component (Mende et al., 2000a, 2000b). The efficiency of the Lyman- $\alpha$ emission per unit energy flux decreases with increasing energy of the precipitating protons (Strickland et al., 1993; Hubert et al., 2001) as a result of processes in the atmosphere competing with the excitation of the relevant $\mathrm{H}(2 \mathrm{p})$ state. The instrument response is of great importance for quantitative interpretation. The SI-12 channel of the FUV instrument is most sensitive to precipitating protons in the energy range between $2 \mathrm{keV}$ and $8 \mathrm{keV}$ (giving wavelengths of $121.82 \mathrm{~nm}$ and $122.07 \mathrm{~nm}$, respectively, i.e. Doppler shifts of $0.25 \mathrm{~nm}$ and $0.50 \mathrm{~nm}$ ) with very little response to ions below $1 \mathrm{keV}$ (Gérard et al., 2000). Proton precipitation also produces secondary electrons resulting from ionizing collisions of the protons and hydrogen atoms with the neutral atmosphere. These electrons have very low mean energy (Strickland et al., 1993; Lummerzheim et al., 2001) and are effective in exciting $\mathrm{O}$ atoms and $\mathrm{N}_{2}$ molecules and thus in producing OI (135.6 nm) and $\mathrm{N}_{2}$ LBH emissions seen by the SI-13/FUV and WIC instruments on IMAGE. Thus, significant fluxes of precipitating protons can, in fact, be an important contributor to these so-called "electron emissions" (Frey et al., 2001, 2002).

\subsection{Cusp behaviour as a function of IMF orientation}

The cusp varies in its location and characteristics with the orientation of the IMF. The numerical models discussed in Sect. 1.2 have generally dealt with southward IMF cases, although they can readily be adapted to northward IMF situations as well (Topliss et al., 2000). The location of the cusp and cusp aurora is known to vary with the $B_{z}$ component of the IMF, both being seen to migrate to lower latitudes when the IMF turns increasingly southward (Burch, 1973; Feldstein and Starkov, 1967; Vorobjev et al., 1975; Horwitz and Akasofu, 1977; Leontyev et al., 1992; Sandholt, 1988; Sandholt et al., 1998; McCrea et al., 2000). In statistical surveys of particle observations by low-altitude satellites, the cusp is, on average, found at lower latitudes when the IMF is southward (Carbary and Meng, 1988; Newell and Meng, 1992; Stubbs et al., 2001). The equatorward motion of the cusp mirrors the inward erosion of the dayside magnetopause due to enhanced reconnection (at latitudes between the magnetic cusps) (Aubry et al., 1970; Maezawa, 1974; Freeman and Southwood, 1988; Petrinec and Russell, 1993; Roelof and Sibeck, 1993).

The anti-parallel and component reconnection hypotheses agree on the site of the reconnection for IMF clock angles $\theta$ of 0 and $180^{\circ}$. For $\theta=180^{\circ}\left(\left[B_{z}\right]_{\mathrm{GSM}}<0,\left[B_{y}\right]_{\mathrm{GSM}}=0\right)$, the reconnection sites will be equatorial and will result in the production of newly-opened flux because the magnetosheath field lines reconnect with closed field lines. On short timescales $(<1 \mathrm{~h})$, the production of newly-opened flux and its assimilation into the polar cap is the dominant driver of dayside ionospheric flow (Cowley and Lockwood, 1992). The newly-opened field lines evolve poleward, their motion at the magnetopause satisfying the Whalén relation (Paschmann et al., 1979; 1986; Sonnerup et al., 1981; 1986; 1990; Johnstone et al., 1986): this means that the field line motion is such that the sheath plasma flows into the magnetopause at the local Alfvén speed. In the southward-IMF case, the curvature force is poleward as is the sheath flow and field lines have to move at roughly the Alfvén speed plus the local sheath flow speed. The motion of newly-opened field lines gives the dispersed cusp precipitation discussed in Sect. 1.2 (Reiff et al., 1977; Onsager et al., 1993; Lockwood, 1995; 1997b).

For $\theta=0^{\circ}\left(\left[B_{z}\right]_{\mathrm{GSM}}>0,\left[B_{y}\right]_{\mathrm{GSM}}=0\right)$, reconnection will be poleward of one or both of the cusps at the sunward edges of the tail lobe(s). A number of topologies are possible (Cowley, 1981). The most likely is with reconnection between the sheath field and already open flux at the sunward edge of the lobe in one hemisphere. This gives reconfigured "over-draped lobe" open field lines on the dayside (Crooker, 1992) and sunward convection as part of a circulation of lobe field lines reflected in the ionospheric polar cap (see references and schematics given by Lockwood, 1998); consequently, a latitudinal ion dispersion signature is produced in the cusp which is in the opposite sense to that for southward IMF (Reiff et al., 1980; Woch and Lundin, 1992). There is evidence that the summer hemisphere is favoured for this reconnection (Crooker and Rich, 1993) and the IMF $B_{x}$ component may also have an influence (Lockwood and Moen, 1999). Sunward flows are seen in observations of the magnetopause bounding the tail lobe (Gosling et al., 1991), which again satisfy the Whalén relation (Paschmann et al., 1990): in other words, the field line velocity is again such that plasma flows from the sheath into the magnetopause at the local Alfvén speed. However, this time the curvature force is opposed to the sheath flow and the field lines move more slowly. (Note that sunward flows can also be seen for reconnection between the magnetosheath and closed geomagnetic field lines taking place equatorward of the cusp but away from the nose of the magnetosphere (e.g. Fedorov et al., 2000).) A further complication is that the overdraped lobe field lines may then reconnect with the "old open" field lines of the opposite hemisphere lobe, giving re-closed field lines (Song and Russell, 1992; Song et al., 1994) and sunward flow. Lockwood (1998) and Lockwood and Moen (1999) 
have discussed the resulting ionospheric flow and cusp/cleft aurora.

The cusp also moves in response to changes in IMF $B_{y}$ (see review by Cowley et al., 1991). For newly-opened field lines, close to the merging gap, the motion reflects the motion of the merging gap caused by the magnetospheric field line mapping. Cowley et al. predicted this motion from the penetration of the IMF $B_{y}$ component into the magnetosphere and showed that in the Northern Hemisphere, the cusp equatorward edge, arising from reconnection near noon, would be in the afternoon sector for $B_{y}>0$ and the morning sector for $B_{y}<0$. These shifts are consistent with observations and are reversed in the southern hemisphere. However, on field lines that have been open for longer, the shift with IMF $B_{y}$ is reversed in sense. This is because for $B_{y}>0$, newlyopened field lines in the northern hemisphere are moved towards dawn by the magnetic curvature force (the "SvalgaardMansurov effect") and for $B_{y}<0$ they move towards dusk: thus field lines that have been open for longer tend to accumulate on the dawn/dusk side for IMF $B_{y}>0$ and $B_{y}<0$, respectively.

1.5 The response of dayside convection to magnetopause reconnection.

Studies of the response of dayside ionospheric convection to changes in the IMF $B_{z}$ component showed a short response time near noon, growing to longer delays at MLT near dawn and dusk. The terms "short" and "longer" in this context refer to typical timescales of the order of 2 and $10 \mathrm{~min}$, respectively, following the time that the IMF change is predicted to have arrived at the dayside magnetopause. Such rapid responses on the dayside were first detected by Nishida (1968a, b) in data from ground-based magnetometers and have also been observed in radar flow data (Rishbeth et al., 1985; Lockwood et al., 1986; Etemadi et al., 1988; Freeman and Southwood, 1988; Todd et al., 1988; Cowley et al., 1998). These studies have used line-of-sight, beamswinging, bistatic coherent scatter and tristatic incoherent scatter radar data. The expansion of the convection equipotentials implied was observed directly by the concomitant ion temperature enhancement (Lockwood et al., 1986, 1993) and in the associated expansion of the currents detected by ground- based magnetometers (Saunders et al., 1992; Lockwood et al., 1999). These observations were explained by Cowley and Lockwood (1992) using the concepts of moving, "adiaroic" (meaning "not flowing across", i.e. nonreconnecting) segments of the open-closed boundary (Siscoe and Huang, 1985, Lockwood et al., 1990) and perturbations of the dayside magnetosphere from equilibrium by the addition of newly-opened flux (Coroniti and Kennel, 1973).

The model of flow excitation by Cowley and Lockwood (1992) is significantly different from the concept that the reconnection electric field maps down field lines into the cusp ionosphere, such that the voltage seen in the Earth's frame of reference is the applied reconnection voltage (Banks et al., 1984; Clauer and Banks, 1988, Ridley et al., 1998). Specif- ically, the models which map the electric fields without allowance for induction effects predict that the ionospheric flows will respond immediately, and in full, to changes in the applied electric field and thus to the IMF $B_{z}$ component. The model of Cowley and Lockwood, on the other hand, predicts an immediate onset of change in convection in response to the IMF $B_{z}$ changes, but that changes in the ionospheric flow will be smoothed by an inductive time constant of the order of 10-15 min which is the time constant for the dayside magnetosphere-ionosphere system to come to equilibrium with the new amount of open flux (Coroniti and Kennel, 1973; Cowley and Lockwood, 1992). Recently, Nishitani et al. (2002) have found observational evidence for both type of responses in SuperDARN radar data and both have been found from numerical modelling of the Cowley-Lockwood concept by Lockwood (2002).

\section{Observations}

We present data from 26 November 2000 relating to proton emission in the cusp. These emissions are monitored in Doppler-shifted Lyman- $\alpha$ by the SI-12 channel of the FUV imager on the IMAGE spacecraft at wavelengths around $121.8 \mathrm{~nm}$, with observations at a variety of wavelengths made from the ground by the UK spectrograph at Longyearbyen, Svalbard and by the EISCAT Svalbard radar. We also compare the Lyman- $\alpha$ emissions with the oxygen emissions seen by the SI-13 channel of the FUV instrument on IMAGE (133.1-138.1 nm). The pattern of convection was observed by the SuperDARN network of coherent-scatter HF radars. The cusp is identified in passes by various DMSP satellites and upstream solar wind and IMF conditions were monitored by both the ACE and Wind spacecraft. The variations in the cusp Lyman- $\alpha$ emission studied in this paper were sufficiently rapid that the ACE-to-Earth propagation delay must be accurately determined before the controlling influence in the IMF can be identified. Consequently, the lag is studied in some detail in the next section.

\subsection{Interplanetary data and the propagation lag to Earth}

Parts (a)-(c) of Fig. 1 show the three components of the Interplanetary Magnetic Field (IMF) in the GSM frame of reference, as seen by ACE (in red) and Wind (in blue). The data are plotted as a function of time at Wind (i.e. the ACE data have been shifted in time by a propagation lag $\delta t_{W}=t_{W}-t_{A}$, where $t_{W}$ is the time at which a certain feature in the IMF variation was seen at Wind and $t_{A}$ is the time that the same feature was seen at ACE). At 15:00UT, the GSE coordinates of Wind were $\left(\mathrm{X}_{\mathrm{GSE}}, \mathrm{Y}_{\mathrm{GSE}}, \mathrm{Z}_{\mathrm{GSE}}\right)=(75.38,98.57,-0.76) R_{E} \quad$ (where a mean Earth radius, $\left.1 R_{E}=6370 \mathrm{~km}\right)$, whereas ACE was at (224.82 35.52-16.53) $R_{E}$. In the GSM frame, ACE's coordinates were $(224.82,30.12,-25.05) R_{E}$ and those of Wind were $(75.38,95.11,-25.9) R_{E}$. In Fig. 1, a constant propagation delay of $\delta t_{W}=12 \mathrm{~min}$ has been used and this aligns 


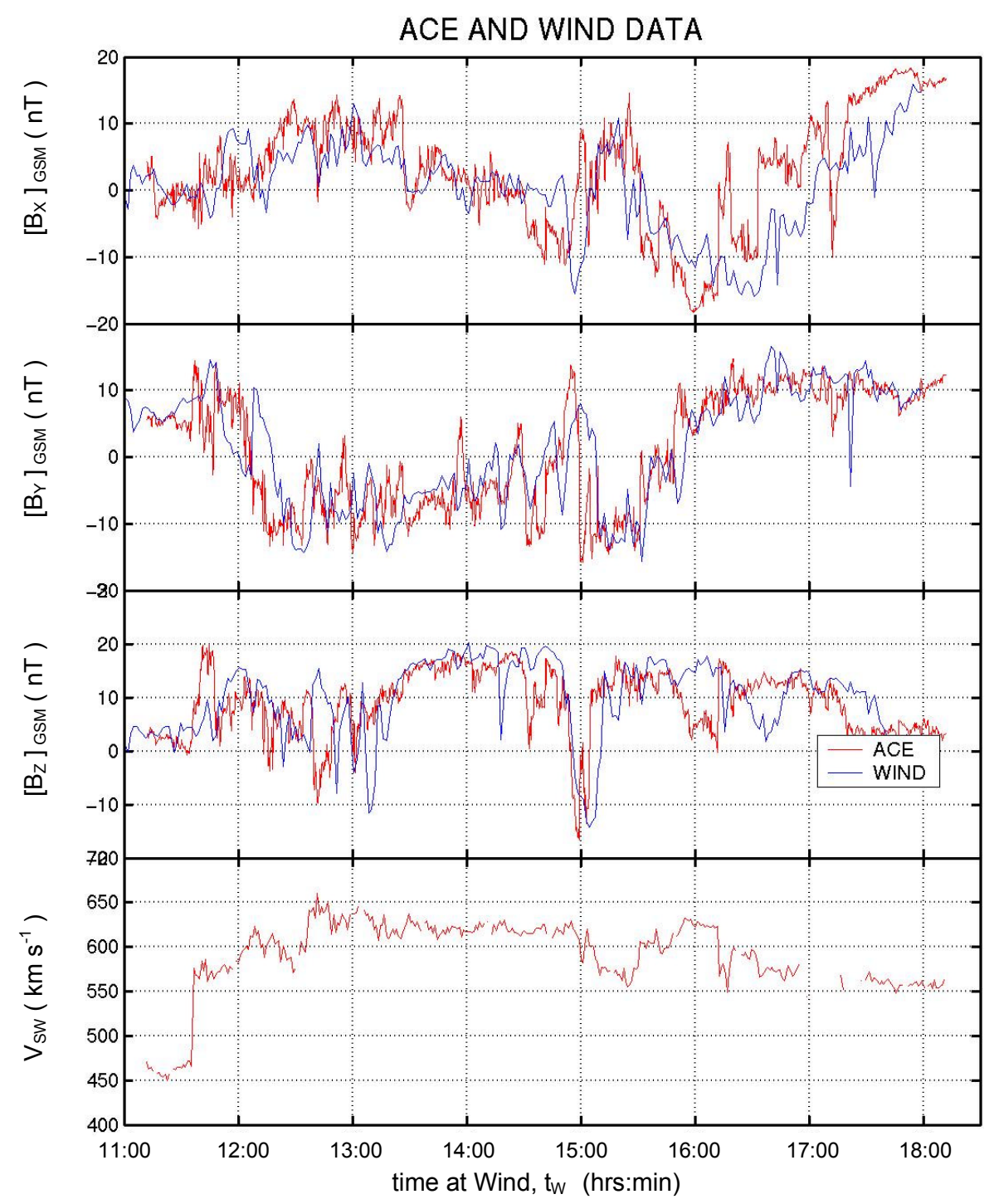

Fig. 1. Interplanetary conditions on 26 November 2000, as detected by the ACE and Wind satellites (red and blue lines, respectively). The top 3 panels give the three components of the IMF in GSM coordinates. The bottom panel gives the solar wind speed observed by ACE. The ACE data are shown as a function of the predicted time at Wind, $t_{W}=t_{A}+\delta t_{W}$, for a constant propagation lag $\delta t_{W}$ of 12 min. which aligns the southward turning seen by the two craft at $t_{W}$ near 14:54 UT.

the southward IMF turning seen by both craft just before 15:00. Figure 1 shows that similar, but not identical, IMF variations were seen by the two craft. Between shortly after 13:00 UT and after 17:00 UT, the IMF was northward except for the brief southward excursion during which both $\left[B_{x}\right]_{\mathrm{GSM}}$ and $\left[B_{y}\right]_{\mathrm{GSM}}$ changed polarity, indicating a crossing from an "away" to a "toward" sector, with the IMF in a "garden-hose" orientation $\left(B_{x} / B_{y}<0\right)$. Figure 1d shows the solar wind speed seen by ACE, $V_{s w}$, which was enhanced at about 11:30 UT and remained high throughout the period of interest, although it fell somewhat (from about $630 \mathrm{~km} \mathrm{~s}^{-1}$ to around $590 \mathrm{~km} \mathrm{~s}^{-1}$ ) during the interval when the IMF was southward.

In Fig. 1 the ACE data have been lagged by a constant $\delta t_{W}=12 \mathrm{~min}$, derived for the southward IMF turning at $t_{W}$ of 14:53 UT. However, this lag clearly does not apply to the subsequent return to northward IMF just after 15:00 which is seen by both craft but with an increased ACE-to-Wind propagation lag of $\delta t_{W}=16 \mathrm{~min}$. One factor in this change in the lag is the decrease in solar wind speed; however, this is far from sufficient as an explanation, showing that the orientation of the IMF structures also changed. Note that without allowance for the actual orientation of the phase front (i.e. using the assumption that the front is normal to the solar wind flow), the ACE-to-Wind delay $\delta t_{W S^{\prime}}{ }^{\prime}$ would be $25 \mathrm{~min}$ for the southward turning, rising to $\delta t_{W N^{\prime}}{ }^{\prime}=26 \mathrm{~min}$ for the northward turning as the solar wind slowed.

Figure 2a shows the garden hose angle $\gamma=$ $\tan ^{-1}\left(\left[B_{x}\right]_{\mathrm{GSE}} /\left[B_{y}\right]_{\mathrm{GSE}}\right)$ observed by both craft around the southward field excursion: these data are shown as a function 


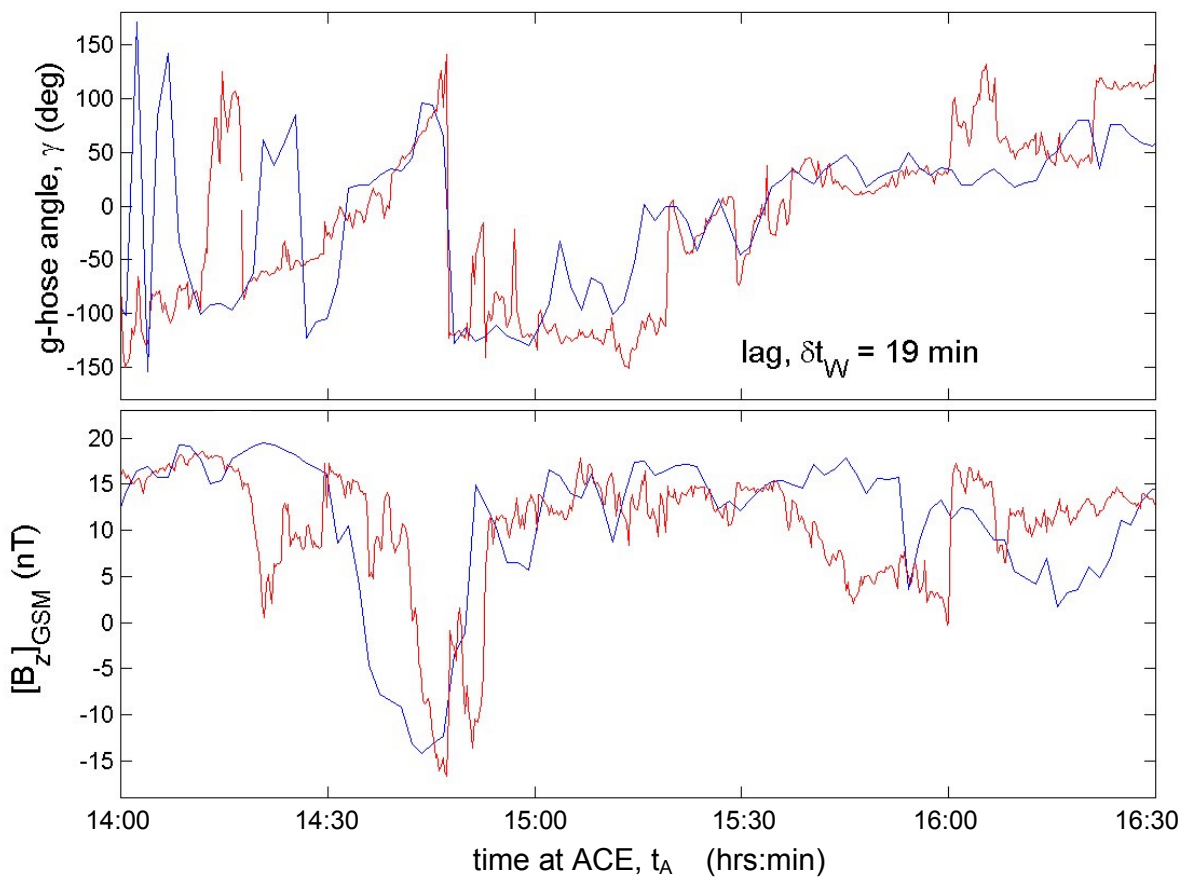

Fig. 2. Detail of the IMF orientation around the southward excursion observed at ACE around 14:45. The top panel shows the garden hose angle $\gamma=\tan ^{-1}\left\{\left[B_{X}\right]_{\mathrm{GSE}} /\left[B_{Y}\right]_{\mathrm{GSE}}\right.$ observed by ACE (red) and Wind (blue). The Wind data are shown as a function of the predicted time at ACE, $t_{A}=t_{W}-\delta t_{W}$, for a constant lag $\delta t_{W}=19 \mathrm{~min}$. This lag aligns the sector crossing seen by both craft during the interval of southward IMF. Apart from some toward-away polarity flips seen by one craft but not the other, agreement is generally good throughout the interval. The bottom panel shows the northward IMF component (in GSM coordinates, $\left[B_{Z}\right]_{\mathrm{GSM}}$ ) for the same lag $\delta t_{W}=19 \mathrm{~min}$ and shows that this lag does not apply to the $\left[B_{Z}\right]_{\mathrm{GSM}}$ data during this interval.

of time at $\mathrm{ACE} t_{A}$ for a lag $\delta t_{W}=19$ min which lines up the sector crossing at $t_{A}$ of 14:45 ( $t_{W}$ of 15:04). An agreement is seen between the garden hose angle $\gamma$ at the two craft: most of the large differences before 14:30 relate to sector crossings (giving $180^{\circ}$ jumps in $\gamma$ ) that pass over one craft but not the other. The lower panel shows the variations of $\left[B_{z}\right]_{\mathrm{GSM}}$ for the same lag. The agreement in $\left[B_{z}\right]_{\mathrm{GSM}}$ is not good for this $\delta t_{W}$ and thus, the region of southward IMF intersected by both craft is not oriented according to the IMF sector structure. Because ACE is not on the Sun-Earth line (rather, it is $\left\{Y^{2}+Z^{2}\right\}^{1 / 2}=39.2 R_{E}$ from it), this orientation must be inferred if the propagation lag to the Earth is to be estimated accurately.

The ACE-to-Wind lag required to match the ACE and Wind observations of the southward turning is $\delta t_{W S}=$ $12 \mathrm{~min}$ at $t_{A}$ of 14:41 ( $t_{W}$ of 14:53) but is $\delta t_{W N}=16 \mathrm{~min}$ for the northward turning at $t_{A}$ of 14:53 ( $t_{W}$ of 15:09). Figure $3 \mathrm{a}$ shows that if we use a linear extrapolation of these lags (Fig. 3b) to later times we continue to obtain a very good agreement between the of $\left[B_{z}\right]_{\mathrm{GSM}}$ variations seen by ACE and Wind. A slightly more rapid linear variation of $\delta t_{W}$ with time would be needed to match the data before the southward turning. However, the features of interest in this paper all occurred during and after the southward IMF turning and thus, the errors in $\delta t_{W}$ before this are not relevant and we adopt the ACE-to-Wind lag variation shown in Fig. $3 b$.

Because ACE does not lie on the $\mathrm{X}$ axis, we need to eval- uate the geometry of the orientation of the southward and northward IMF turnings to estimate the corresponding ACEto-Earth propagation lags, $\delta t_{E S}$ and $\delta t_{E N}$. Because ACE and Wind lie at a similar $Z$ (near $-25 R_{E}$ in the GSM frame) they can give information on the orientation of IMF changes in the GSM XY frame. The orientations of the northward and southward turnings in this plane, deduced from the ACE and Wind data, are shown in Fig. 3c. To allow for the effect of the bow shock and the draping of the field lines, we make use of the gas dynamic predictions by Spreiter et al. (1966). Because the flow velocity at the nose of the magnetosphere is zero in these predictions, field lines actually take an infinite time to reach the nose of the magnetosphere. Any reconnection at the magnetopause means that field lines do not stagnate at the nose. For example, for a reconnection rate of $1 \mathrm{~m} \mathrm{~V} \mathrm{~m}^{-1}$ and a sheath field of $20 \mathrm{nT}$, the inflow velocity towards the reconnecting magnetopause from the sheath side will be at $50 \mathrm{~km} \mathrm{~s}^{-1}$, i.e. of the order of $V_{s w} / 10$. In the gas dynamic predictions, we note that the field line that has reached $V_{s w} / 10$ in the sheath is draped such that its extrapolation from interplanetary space into the magnetosphere cuts the $X$ axis very close to the Earth (i.e. near $X=0$ ). This is true for both IMF orientations studied by Spreiter et al. (with the IMF at $\pi / 2$ and $\pi / 4$ with respect to the $X$ axis). This means we can allow for the field line draping by equating the time for the field line to reach the dayside magnetopause to the time that it would take to reach $X=0$ in the absence 

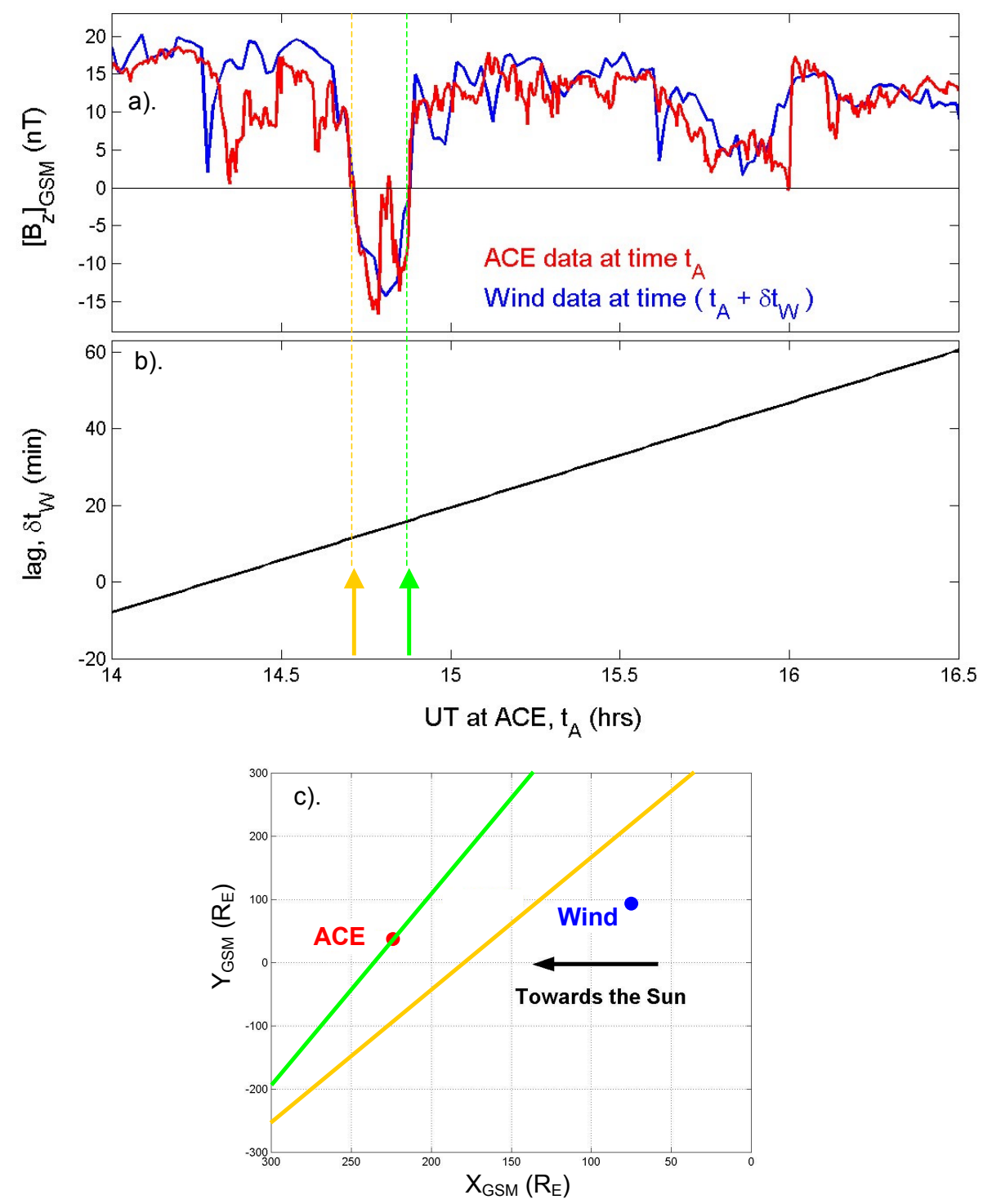

Fig. 3. (a) The northward IMF component (in GSM coordinates, $\left[B_{Z}\right]_{\mathrm{GSM}}$ ) as a function of time at ACE $t_{A}$, as observed by ACE (red) and Wind (blue) for the linear variation with time of the lag $\delta t_{W}=t_{W}-t_{A}$, shown in (b). (c) shows the inferred orientations and locations of the southward (orange) and northward (green) turnings of the IMF at 14:53 UT. The plot is in the GSM (XY) frame, in which ACE's coordinates were $(224.82,30.12,-25.05) R_{E}$ and those of Wind were $(75.38,95.11,-25.9) R_{E}$.

of the magnetosphere and bow shock. This procedure yields $\delta t_{E S}=42 \mathrm{~min}$ and $\delta t_{E N}=45 \mathrm{~min}$ and thus, we predict that the southward and northward turnings should be seen in the ionosphere at 15:23 and 15:38 UT, respectively. The linear variation of the ACE-to-Earth lag $\delta t_{W}$, shown in Fig. 3(b), strongly implies that we can assume a linear variation to interpolate and extrapolate the ACE-to-Earth lag $\delta t_{E}$ from $\delta t_{E S}$ and $\delta t_{E N}$. Comparison with data taken by the IMAGE spacecraft and the SuperDARN radars, presented below, confirm these delay estimates. Note that without an allowance for the orientation of the phase fronts (i.e. assuming that phase fronts were normal to the solar wind flow direction), yields ACE-to-Earth lags of $\delta t_{E S^{\prime}}=37 \mathrm{~min}$ and $\delta t_{E N^{\prime}}=40 \mathrm{~min}$ for the southward and the northward turnings, respectively.
The inferred orientation of the southward and northward IMF turnings, shown in Fig. 3c, imply that at $[Y]_{\mathrm{GSM}}=Y p \ll 0$ the two will meet, meaning that the region of southward IMF in the $[X Y]_{\mathrm{GSM}}$ plane was triangular in shape with the apex of the triangle at $Y_{p}$.

Because both ACE and Wind lie to the south of the $[X Y]_{\mathrm{GSM}}$ plane $\left(Z_{\mathrm{GSM}} \approx-25 R_{E}\right)$, the orientation of the IMF change fronts in the $[X Z]_{\text {GSM }}$ plane will also influence the ACE-to-Earth lag, $\delta t_{E}$. Determination of the orientation in this plane requires data from a third interplanetary craft at a different $Z_{\mathrm{GSM}}$. Because we have no such data, this introduces an uncertainty in the lag estimates. For example, variation of the front orientation of $\pm \pi / 4$, with respect to the $Z_{\mathrm{GSM}}$ axis in the $[X Z]_{\mathrm{GSM}}$ plane, would introduce an uncer- 

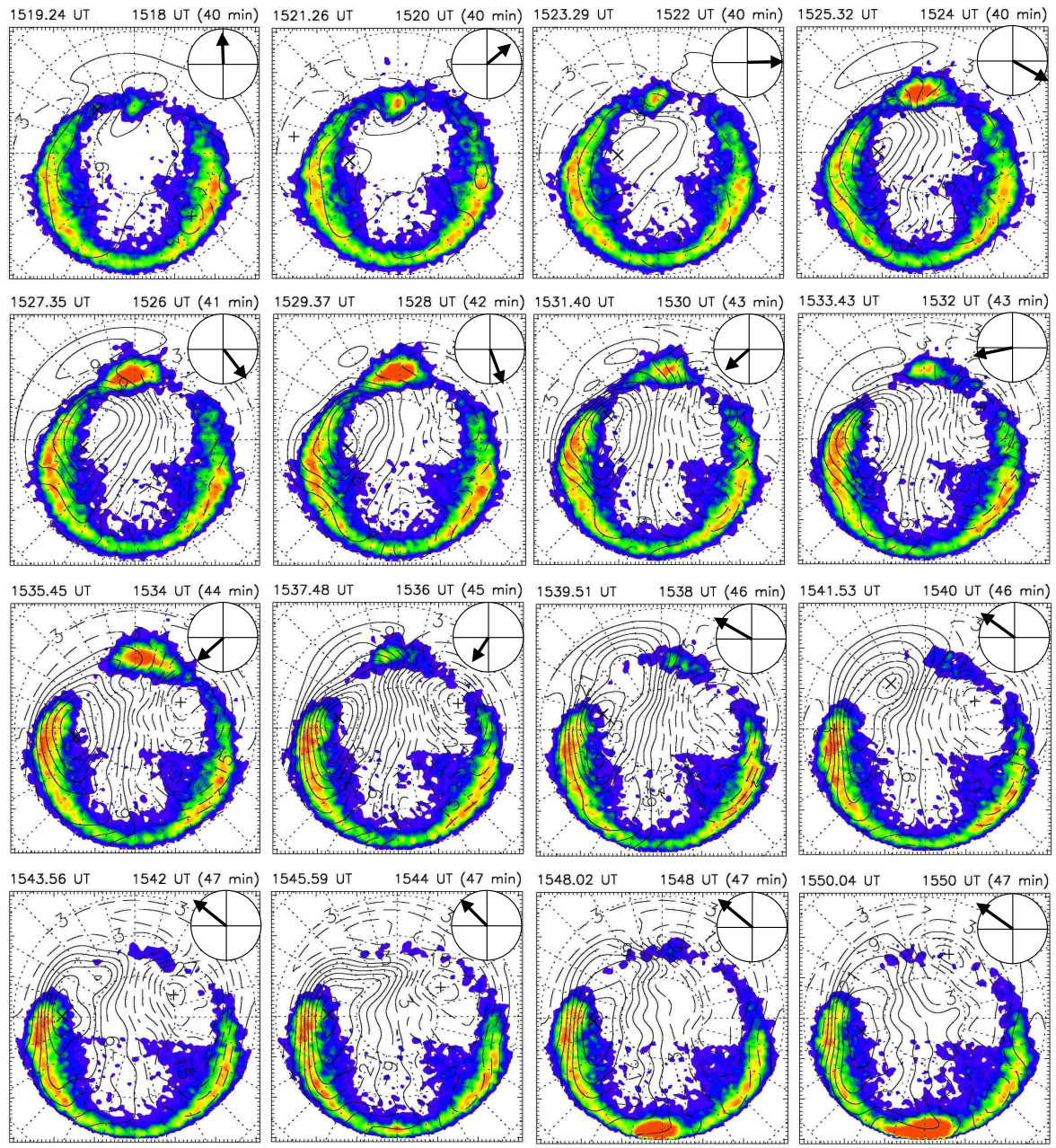

Fig. 4. Global images of the Doppler-shifted Lyman- $\alpha$ emission seen by the FUV instrument on the IMAGE spacecraft, with convection potential contours from the SuperDARN HF coherent radar network. Images are 5-s integrations, taken once every $122 \mathrm{~s}$. The intensity scale is the same in each frame - absolute intensities are given by the scale in Fig. 5. The convection patterns are produced by a model fit to all line-of-sight velocity observations, the model used being determined by the IMF orientations seen by ACE for the propagation lags discussed in the paper. Streamlines are $6 \mathrm{kV}$ apart. given above each frame is the time of the FUV image, the start time of the closest radar scan, and (in parentheses) the ACE-to-Earth propagation lag $\delta t_{E}$ used for the convection model input. The vector in the top right of each frame is the lagged IMF in the $\left[B_{Z}\right]_{\mathrm{GSM}}$ (up the page) $-\left[B_{Y}\right]_{\mathrm{GSM}}$ (to the right) frame, the circle corresponding to a magnitude of $15 \mathrm{nT}$.

tainty in the lag $\delta t_{E}$ of \pm 4 min.

\subsection{IMAGE data}

Figure 4 shows the sequence of images of the Dopplershifted Lyman- $\alpha$ emission at wavelength of $121.8 \mathrm{~m}$, observed by the FUV-SI2 imager on the IMAGE spacecraft. These images were recorded in 5-s integration intervals, with deconvolution of the effect of spacecraft spin. Successive images are separated by the spacecraft spin period of $122 \mathrm{~s}$. Magnetic noon is at the top of each frame and concentric dotted circles are $10^{\circ}$ apart in invariant latitude. The time of recording of each image is given above the top left-hand corner of each frame. Within each frame, the lagged IMF vector is shown in the top right-hand corner. This vector is compiled from one-minute averages of the IMF components and is plotted in the $\left[B_{Z}\right]_{\mathrm{GSM}}-\left[B_{Y}\right]_{\mathrm{GSM}}$ frame (shown, respectively, as up the page and to the right) with the circle denoting an amplitude $\left(\left[B_{Z}\right]^{2}+\left[B_{Y}\right]^{2}\right)^{1 / 2}$ of $15 \mathrm{nT}$. The ACE-toEarth propagation lag $\delta t_{E}$ used is the same as that calculated in Sect. 2.1 and the value of $\delta t_{E}$ for each frame is given in parentheses just above the IMF plot. It can be seen that the IMF at the magnetopause was northward (in the $+\left[B_{Z}\right]_{\mathrm{GSM}}$ direction) for the first frame shown (15:19UT) but subsequently rotated smoothly clockwise, such that it was in the $+\left[B_{Y}\right]_{\mathrm{GSM}}$ direction by $15: 23$, in the $-\left[B_{Z}\right]_{\mathrm{GSM}}$ direction by $15: 30$ and in the $-\left[B_{Y}\right]_{\mathrm{GSM}}$ direction by $15: 34$. After a brief anti-clockwise rotation, which returned the IMF to $\left[B_{Y}\right]_{\mathrm{GSM}}<0$ and $\left[B_{Z}\right]_{\mathrm{GSM}}<0$, the vector again rotated clockwise before settling down to a stable orientation with $\left[B_{Y}\right]_{\mathrm{GSM}}<0$ and $\left[B_{Z}\right]_{\mathrm{GSM}}>0$ after 15:38.

In each image, the main auroral oval can be seen, but 
it is the brightening, fading and motions of the bright spot around noon that we are concerned with here. The first major brightening was at 15:21:26 UT, after which the spot grew and brightened before fading again at 15:31:40 UT and re-brightening at 15:35:45 UT. This second brightening was shorter-lived than the first and the bright spot has almost completely disappeared by 15:43:36 UT.

In addition to this modulation of the intensity of the spot, its centre migrated westward, being slightly eastward of noon at 15:28, but slightly westward of noon by $15: 36$. This migration is consistent with the change in the merging gap location expected for the change in IMF $B_{y}$ from positive to negative in the sector crossing, as seen by ACE at around 14:45. The westward motion of the spot began at about 15:30, giving an ACE-to-Earth propagation lag (45 min) which is similar to that derived for the changes in the IMF $B_{z}$ component. The motion is consistent with that of the merging gap (i.e. the footprint of the reconnection site) rather than that of the cusp plume (Cowley et al., 1991). This is as observed in the statistical survey of the SI-12/FUV cusp proton aurora images by Frey et al. (2002). From this we infer that in the bright spot, the imager was observing precipitation along the most recently-opened field lines (i.e. the elapsed time since reconnection is small), close to the reconnection site. In Sect. 5 we use a model of cusp precipitation, proton aurora excitation and the SI-12/FUV response to show that the emission indeed peaks on field lines of low elapsed time since reconnection, and thus relatively close to the ionospheric projection of the reconnection $\mathrm{X}$-line.

The intensifications in the cusp aurora seen around noon consititute the growth phase of a substorm, the onset of which can be seen near midnight at 15:43:46 UT (the third from the last frame of Fig. 4) with subsequent expansion clearly visible in the last two frames. This substorm will be studied in a subsequent paper.

These IMAGE/FUV data were integrated into 48 MLT sectors, each $30 \mathrm{~min}$ wide, to give latitudinal profiles. Parts (a) and (b) of Fig. 5 show emissions in the 12:00-12:30 MLT sector: the intensity is plotted as a function of latitude and time (in min after 15:00). The two brightenings seen in Fig. 4 can be identified and can also be seen to have coincided with equatorward motion of both the peak emission $I_{\max }$ and of the latitudinal band of emission (roughly delineated by the yellow lines which show the smoothed variation of the latitudes where the intensity fell to $I_{\max } / 2$ ). Figure $5 \mathrm{~b}$ is the Doppler-shifted Lyman- $\alpha$ emission at $121.8 \mathrm{~nm}$ and is excited by proton precipitation: Fig. 5a is the corresponding plot, on the same intensity scale, for the $135.6 \mathrm{~nm}$ doublet of oxygen OI emissions, observed by the SI-13 channel of FUV. As discussed in Sect. 1.3, this OI emission is produced not only by primary electron precipitation, but also by secondary electrons generated by the ion precipitation (Hubert et al., 2001; Frey et al., 2001, 2002). Figure 5a shows that the OI emission had many similar features to the proton emission shown in Fig. 5b. The similarities between the latitudinal structures and the temporal variations seen in these two emissions is partly caused by the fact that a significant fraction of

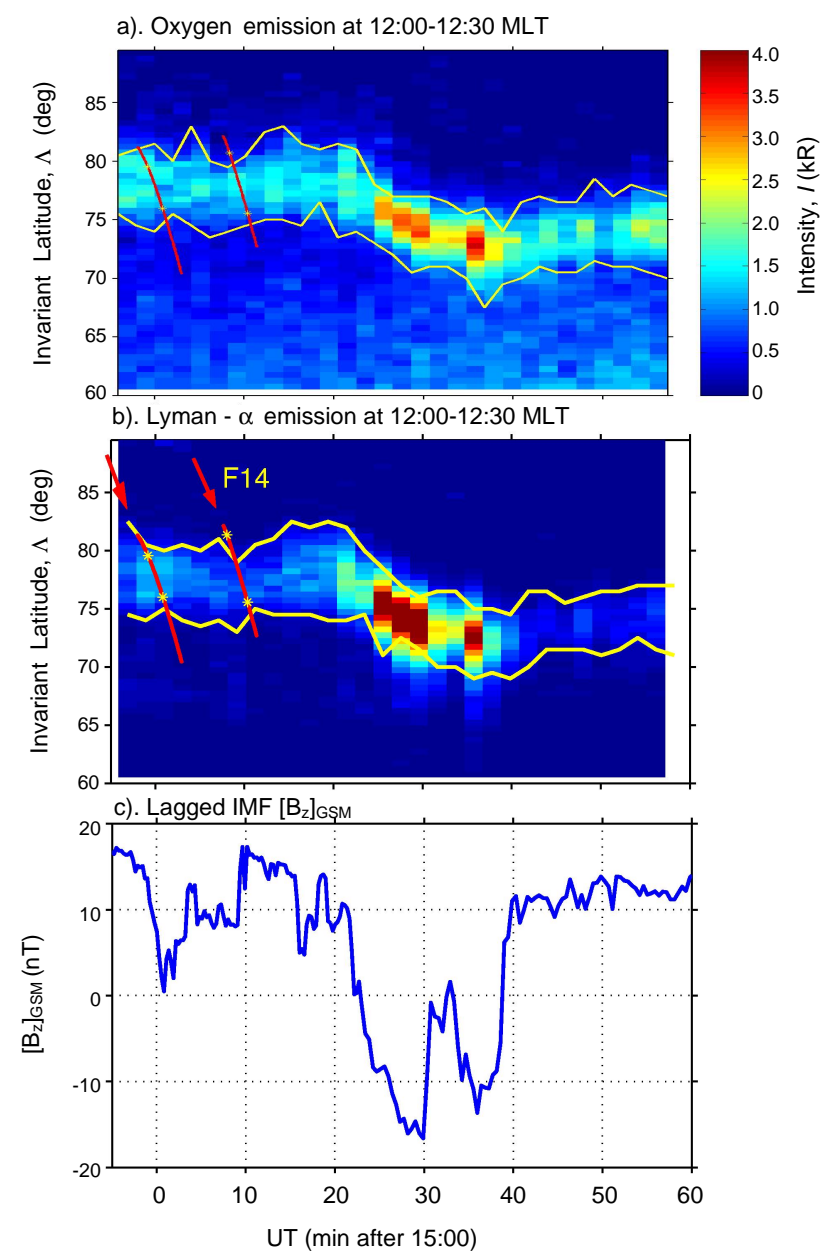

Fig. 5. Keograms of (a) the oxygen $(135.6 \mathrm{~nm})$ and (b) the Dopplershifted Lyman- $\alpha(121.8 \mathrm{~nm})$ emission intensities seen by the FUV instrument in the 12:00-12:30 MLT sector. (c) shows the IMF $B_{z}$ component in GSM coordinates, lagged by the predicted ACE-toEarth propagation lag $\delta t_{E}$.

the OI emission is caused by secondary electrons produced by proton precipitation, but also because quasi-neutrality is maintained in the cusp region (Burch, 1985) which means there is a complex link between the primary fluxes of electrons and protons.

Figure $5 \mathrm{c}$ shows the IMF $\left[B_{z}\right]_{\mathrm{GSM}}$ component, as observed at ACE and displayed here as a function of time in the ionosphere, $t_{i}=t_{A}+\delta t_{E}$, predicted for a linear variation of the ACE-to-Earth propagation lag $\delta t_{E}$ that is defined by $\delta t_{E S}=42 \mathrm{~min}$ and $\delta t_{E N}=45 \mathrm{~min}$ for the southward and northward turnings, respectively (as discussed in Sect. 2.1). Considerable correspondence between the IMAGE data and the lagged IMF data can be seen. In particular, the aurora (in both proton and oxygen emissions) began to move southward, immediately after the observed southward turning of the IMF, and is predicted to have reached the magnetopause. This is consistent with the erosion of the dayside magnetopause and the corresponding cusp migration discussed in Sect. 1.4. Subsequently, the bands of emission began to re- 


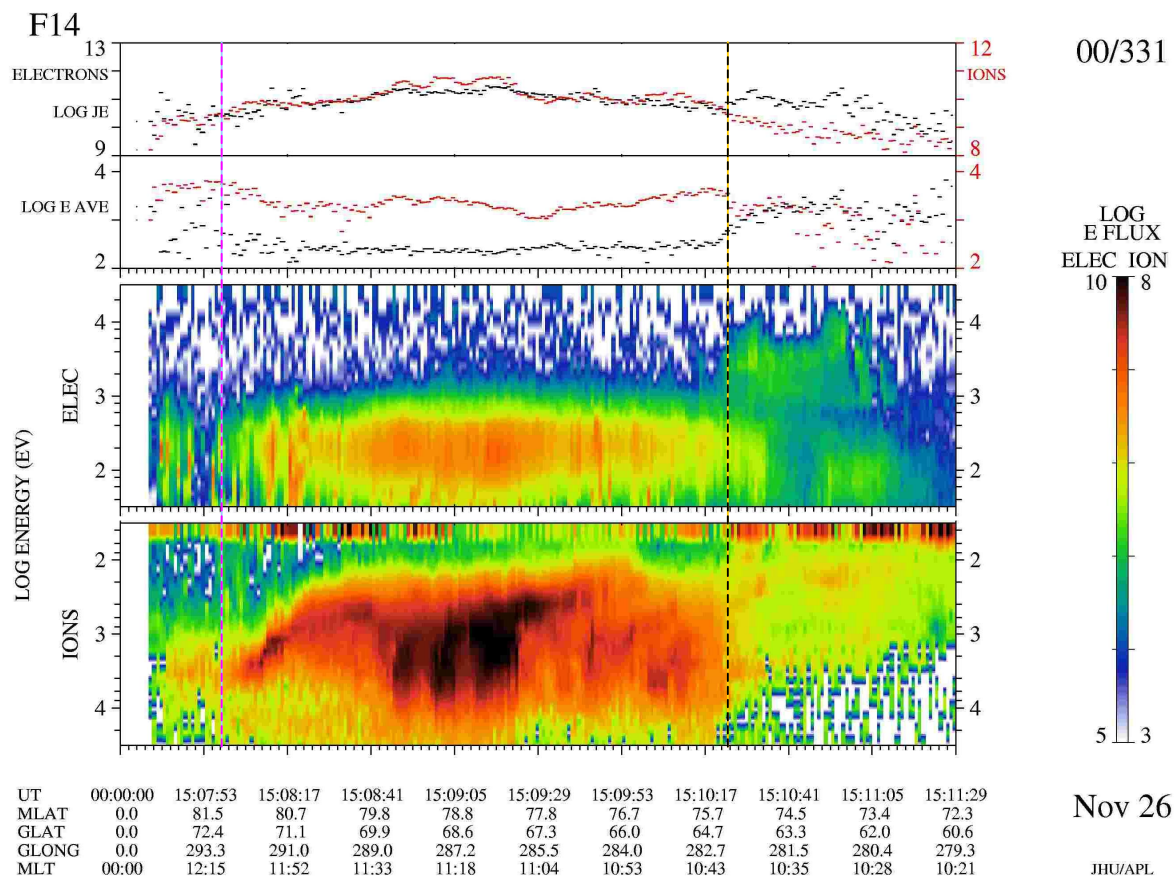

Fig. 6. DMSP F14 observations of the cusp pass around the 12 MLT meridian at 15:07:58-15:10:27 UT. The top panel shows the integrated energy flux of electrons (in black) and ions (in red). The second panel shows the corresponding average energies. The upper spectrogram shows the differential energy flux of electrons, contoured as a function of energy and observation time. The bottom panel shows the same for ions, with the ion energy scale inverted. The blue and mauve dashed line gives the poleward edge of the cusp precipitation and the orange and black dashed line gives the equatorward edge.

lax back poleward with the arrival of the effects of the northward turning. The peak emission intensity was also clearly enhanced when the lagged IMF pointed southward.

\subsection{DMSP data}

The red lines in Figs. 5a and b show passes of DMSP (Defense Meteorological Satellite Program) satellites at MLT close to the 12:00-12:30 UT range used in Fig. 5. The yellow points on each mark the poleward and equatorward edges of electron and ion precipitation which are classified as cusp (Newell and Meng, 1992). The particle data for the second of these two passes, by the DMSP-F14 spacecraft, are given in Fig. 6. The middle panel shows the differential energy flux of observed electrons as a function of energy and observation time. The lower panel is a similar spectrogram plot for the observed ions, but the ion energy scale has been inverted. As the satellite passed equatorward, just after 15:10:17 UT (black and yellow dashed line), it observed a low-latitude edge of low-energy, magnetosheath ions and electrons and enters a region where there are higher-energy magnetospheric electrons. This is consistent with the craft crossing the open-closed field line boundary near this time (Lockwood, 1997a, b; 1998). Poleward of this is a region of sheath-like ion and electron precipitation, which is classified as cusp. Towards the poleward edge of the cusp (which is marked by the dashed mauve and light blue line) is an ion dispersion signature, with the low-energy ion cutoff decreas- ing with decreasing latitude. This "reverse dispersion" reveals a northward-IMF lobe reconnection site and sunward convection and is consistent with the lagged IMF orientation which was northward at this time (just prior to the southward turning - see Fig. 5). The yellow points shown in Fig. 5 are the satellite locations for 15:08:00 and 15:10:25 UT, marking the boundaries of the cusp precipitation, as defined in Fig. 6, and agree well with the boundaries of the latitudinal band of emission seen at both wavelengths. Note that the satellite traversed the cusp between 12:15 and 10:45 MLT, whereas the intensities in Fig. 5 are for 12:00-12:30 MLT. Thus we expect differences between the precise latitudes of the cusp boundaries due to the longitudinal variations; nevertheless, from the DMSP data we can definitively identify the band of emission in both proton and oxygen emissions (Figs. 5b and a, respectively) as being the cusp.

\subsection{SuperDARN global convection observations}

Superposed on the proton aurora images shown in Fig. 4 are the convection flow streamlines deduced using a convection model fit to observations by the network of Northern Hemisphere SuperDARN HF radars. These streamlines are derived by fitting the convection model to the observed line-ofsight velocities (Ruohoniemi and Baker, 1998). The model is driven by the upstream IMF conditions and thus, it is very important to quantify correctly the lag from ACE to the Earth for these high resolution response studies. The radar scan 
used is at the time closest to the FUV image, the start time of which is given above the top right corner of each frame, along with the propagation lag $\delta t_{E}$ in parentheses. The $\delta t_{E}$ values are those used in Fig. 5c. The equipotentials are $6 \mathrm{kV}$ apart in each panel.

At 15:19:24 UT the flow was weak and disorganised, but began to respond with a localised flow vortex at 15:21:26 around the brightening cusp proton aurora spot near 12:00 MLT. This appears to be the response to the clock angle increase; however, the lagged IMF was still northward at this time. By 15:23:29 UT the localised vortex had grown into a larger scale southward IMF flow pattern, dominated by the dusk cell and with a westward flow from a reconnection site that appears to be in the afternoon sector; this is consistent with the positive IMF $B_{y}$ at the time of the southward turning. During the interval 15:25:32-15:37:48 UT, the westward flow poleward of the proton cusp emission gradually decayed and eventually became weakly eastward; this is also consistent with the IMF $B_{y}$ change to negative during the period of southward IMF and the westward migration of the proton aurora. The flow response to the IMF $B_{y}$ change is the same as was observed in conjugate ionospheres by Greenwald et al. (1990), using SuperDARN radars. In this interval, the flow was enhanced but the increase lagged behind the brightening of the cusp aurora. (The flow within the cusp region had an extended peak between 15:37:48 and 15:41:53 UT, whereas the proton aurora peaked at 15:30:00 UT.)

Thus, the dayside flows responded to the IMF changes in the manner expected, but this response followed the brightness fluctuations of the cusp proton aurora. The effects of the magnetic curvature force giving IMF $B_{y}$-dependent eastward or westward flow can be seen in Fig. 4 poleward of the proton cusp aurora, as would be expected because the proton emissions are seen at small elapsed times since reconnection, close to the merging gap. Section 7.1 discusses how the aurora and flows were very much as predicted by the model of ionospheric convection excitation for the production of newly-opened flux by Cowley and Lockwood (1992).

\section{Comparison of lagged interplanetary data with cusp auroral intensities}

Figure 7 shows the lagged interplanetary data recorded by ACE and compares them with the peak Doppler-shifted Lyman- $\alpha$ emission intensity $I_{\max }$ at 12:00-12:30 MLT, the latitudinal motion of this peak and the transpolar voltage derived from the SuperDARN convection data. The propagation lags between ACE and Earth's cusp ionosphere $\delta t_{E}$ have been estimated as in Fig. 4 and $5 \mathrm{c}$, giving the lagged ACE data variations shown in panels (b) and (c) of Fig. 7. Figure $7 \mathrm{~b}$ shows the IMF clock angle, $\theta=$ $\tan ^{-1}\left(\left|\left[B_{Y}\right]_{\mathrm{GSM}}\right| /\left[B_{z}\right]_{\mathrm{GSM}}\right)$, and Fig. 7c shows the solar wind proton concentration $\mathrm{N}_{\mathrm{H}+}$. For comparison, Fig. 7a shows the peak Lyman- $\alpha$ emission intensity and Fig. 7e gives the velocity of motion of that peak (positive poleward). The latter is found from the difference in the latitude between

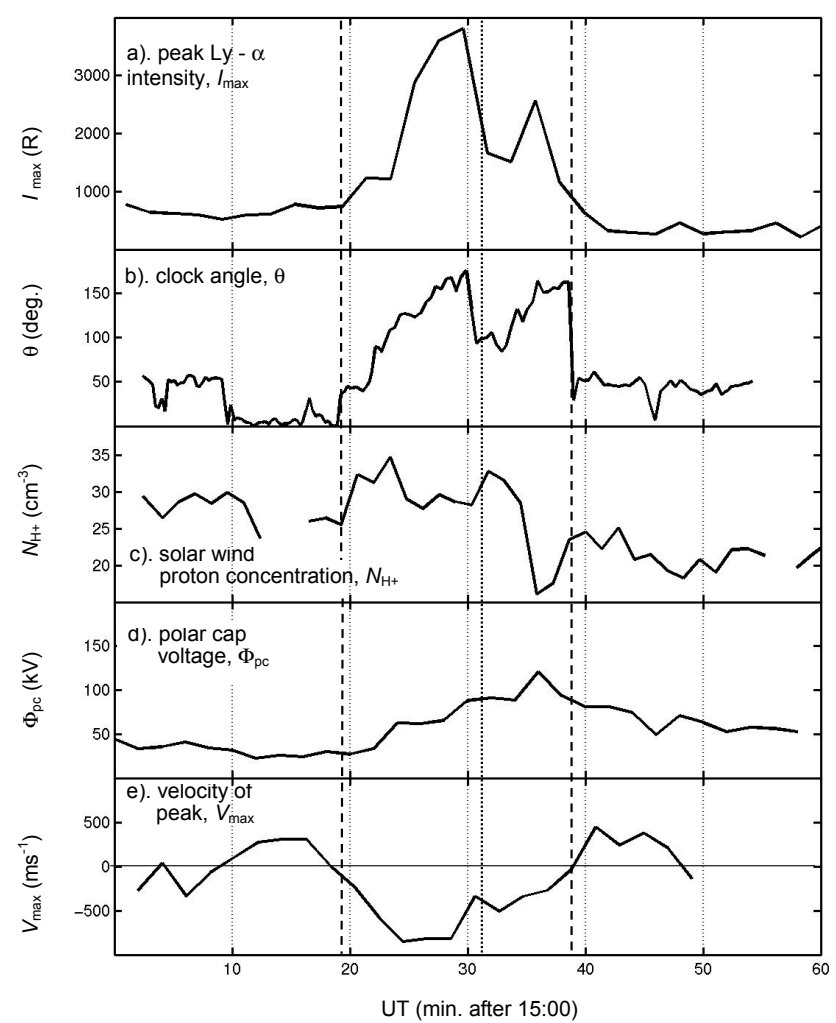

Fig. 7. Variations of parameters observed during the brief intensification of the cusp aurora: (a) $I_{\max }$, the peak Doppler-shifted Lyman- $\alpha$ emission intensity seen along the meridian keogram from SI-12/FUV data integrated over 12:00-12:30 MLT (Fig. 5); (b) $\theta$, the IMF clock angle in GSM coordinates, as observed by ACE ; (c) $\mathrm{N}_{\mathrm{H}+}$, the proton concentration in the solar wind seen by ACE; (d) $\Phi_{\mathrm{pc}}$, the transpolar voltage from the model fit to the SuperDARN radar data; and (e) $V_{\max }$, the meridional phase velocity of motion of the peak Lyman- $\alpha$ emission. All ACE data have been lagged by the derived ACE-to-Earth propagation delay $\delta t_{E}$.

successive images and is therefore somewhat noisy. To reduce this noise, the latitude of the peak seen in Fig. 5b has been averaged with the mean latitudes of the poleward and equatorward emission band boundaries. Figure $7 d$ shows the transpolar voltage $\Phi_{\mathrm{pc}}$ scaled from the convection patterns shown in Fig. 4.

The vertical dashed lines in Fig. 7 mark the times between which the clockwise IMF rotation, as shown in Fig. 4, took place: these lines mark the times when the first and last changes in $\theta_{\mathrm{IMF}}$ are predicted to have reached the magnetopause. The dotted line shows the time when $\theta_{\mathrm{IMF}}$ was near $\pi / 2$, prior to the brief return to a more southward orientation. It can be seen that the peak proton emission varied with $\theta$. The intensity of the second peak was not proportionally as great as the first but this is, in part, caused by the variation in the solar wind proton concentration $\mathrm{N}_{\mathrm{H}}$ which went through a brief minimum at this time (Fig. 7c). Figure 7(e) shows that the cusp aurora began to migrate southward (velocity of motion of peak $V_{\max }<0$ ) when $\theta$ began to increase, but began to relax poleward $\left(V_{\max }>0\right)$ as soon as the clock angle re- 

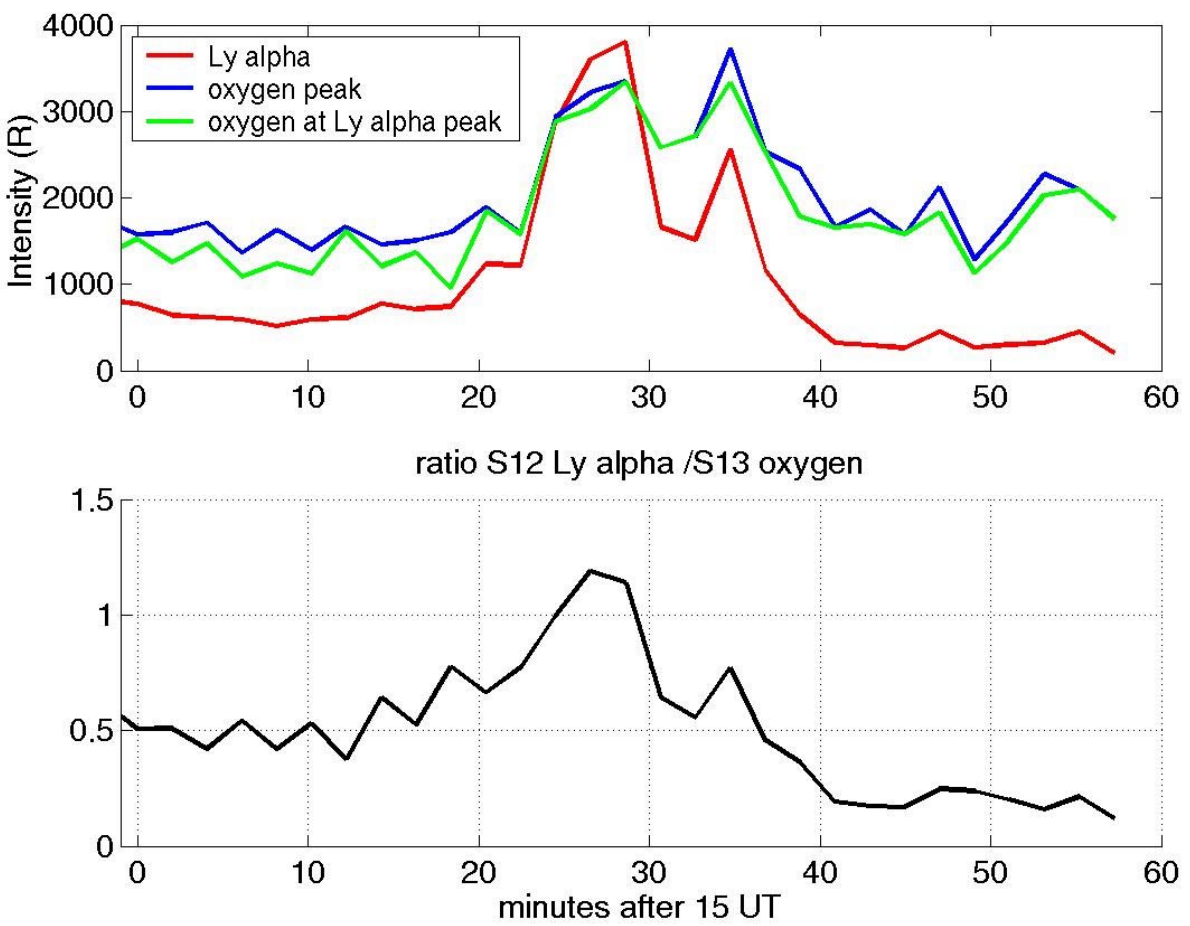

Fig. 8. (Top) The time variations of the peak Lyman- $\alpha$ emission, $I_{\max }$ (red), the peak oxygen emission (blue) and the oxygen emission at the location of the peak Lyman- $\alpha$ emission, $\left[I_{O}\right]_{\max }$. (Bottom) The ratio of the emission intensities $I_{\max } /\left[I_{O}\right]_{\max }$ at the Lyman- $\alpha$ peak. All are shown for integrations over 12:00-12:30 MLT.

turned to small values with the northward turning. As for the intensity of the emission shown in Fig. 7a, the latitudinal motion shown in Fig. 7e reveals the effect of the brief period of $\theta \approx \pi / 2$ around the dotted line. The transpolar voltage $\Phi_{\mathrm{pc}}$, as shown in Fig. 7d, began to rise a few minutes after the first response of the proton aurora (in latitude and intensity). It subsequently peaked at 15:37 UT and decayed with roughly the same constant with which it rose (of the order of 10-15 min).

Figure 8a shows the peak emission intensities $I_{\max }$ for the 12:00-12:30 MLT sector. The red line is the observed peak Doppler-shifted Lyman- $\alpha$ proton intensity, the blue is the peak oxygen OI emission and the green is the OI emission at the latitude of peak proton emission. The similarity of the behaviour of the emissions at the two wavelengths, discussed earlier in connection with Fig. 5, means that the peak intensity for the two wavelengths is found at very similar latitudes (compare Figs. 5a and b), and the blue and green lines in Fig. 8 are very similar. The bottom panel of Fig. 8 shows the ratio of the Lyman- $\alpha$ to the oxygen OI intensities at the peak of the Lyman- $\alpha$ for this MLT sector. In this paper, we will not consider the absolute values of these intensities because that will depend on the details of the conversion of SI-12 and SI-13 counts into intensities. However, we note that similar variations in all intensities were observed, with the same double brightening waveform as noted above for the Doppler-shifted Lyman- $\alpha$. However, the bottom panel shows that the ratio of Lyman- $\alpha$ to OI intensities increased, particularly during the first brightening. The variation of the OI emission is, at least in part, explained by the emission caused by secondary electrons produced by the proton precipitation. It is important to note that the ratio of the emissions shows that the variation with IMF clock angle was proportionally greater for the proton precipitation than for the electron precipitation. Indeed, due to the effect of secondary electrons produced by proton precipitation, it is quite possible that the clock angle dependence was present only in the proton precipitation. In Sect. 7.2 we discuss the importance of the question of whether or not the electron precipitation that contributes to the OI emission also has a clock angle dependence.

Figure 9 shows a scatter plot of the peak proton emission intensity $I_{\max }$ as a function of the lagged clock angle observations. However, as noted above, there were also variations in the solar wind proton concentration $\mathrm{N}_{\mathrm{H}+}$. Given that the cusp proton precipitation number flux varies approximately linearly with the solar wind concentration (Lockwood, 1995) and that the Doppler-shifted Lyman- $\alpha$ emission (and the SI$12 /$ FUV response) will depend linearly on this flux (if all other parameters remain constant, Gérard et al., 2001), we can make a linear correction to Fig. 9 to allow for variations in $\mathrm{N}_{\mathrm{H}+}$. The result is shown by the points in Fig. 10 which presents the normalised intensity $I_{\max }\left\{<\mathrm{N}_{\mathrm{H}+}>/ \mathrm{N}_{\mathrm{H}+}\right\}$ as a function of lagged $\theta$, where $<\mathrm{N}_{\mathrm{H}+}>$ is the average over the full interval presented in Fig. 7. The lines show modelled variations which will be discussed in Sect. 5. 


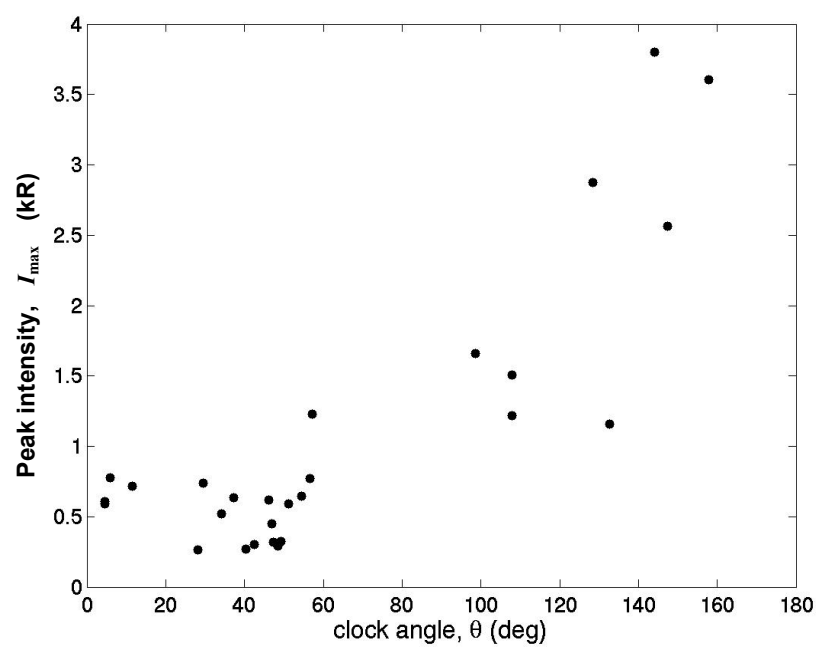

Fig. 9. Scatter plot of the peak Lyman- $\alpha$ emission intensity, $I_{\max }$, integrated over 12:00-12:30 MLT, against the IMF clock angle in GSM observed by ACE, $\theta$. The ACE data have been lagged by the derived ACE-to-Earth propagation delay $\delta t_{E}$.

\section{Effects of motion of the reconnection site}

Even for component merging, the locations of the reconnection sites on the dayside magnetopause will be a function of the IMF clock angle. The three rows of Fig. 11 show schematically three likely configurations relevant to the data presented here. For each row, the left-hand figure is a view of the magnetosphere from the dusk flank (with the Sun to the left and northward up the page), the centre figure is the view from the Sun (with dawn to the left and northward up the page) and the right-hand figure is a view looking down on the Northern Hemisphere ionospheric polar cap (with noon at the top and dawn to the right). The dashed and dotted lines in the magnetospheric views are the magnetopause and the bow shock, respectively, thin solid lines with arrows are field lines, and the dashed arrow shows the evolution of the point where a newly-opened field line threads the magnetopause. In the ionospheric (right hand) plots, the dashed line is a non-reconnecting open-closed field line boundary (OCB) and the thick solid line is the merging gap, the ionospheric footprint of an active reconnection $\mathrm{X}$ line: thin solid lines with arrows are flow streamlines and the dashed line superposed on a streamline shows the evolution of the newlyopened field line shown in the magnetospheric views. The grey area is where cusp precipitation occurs along newlyopened field lines. The top row is for subsolar reconnection with IMF $B_{Z}<0, B_{Y}<0$. The second row is for lobe reconnection with $B_{Z}>0, B_{Y}>0$ and the bottom row is for $B_{Z}>0, B_{Y}>0$, but this time with reconnection near the magnetic cusp which opens closed field lines. Similar flow patterns would be expected for anti-parallel reconnection, but the MLT of the merging gap would be smaller in the equivalent to Fig. 11a. In this context, it is worth noting that Fig. 4 shows a merging gap of about $3 \mathrm{~h}$ in MLT extent. In all

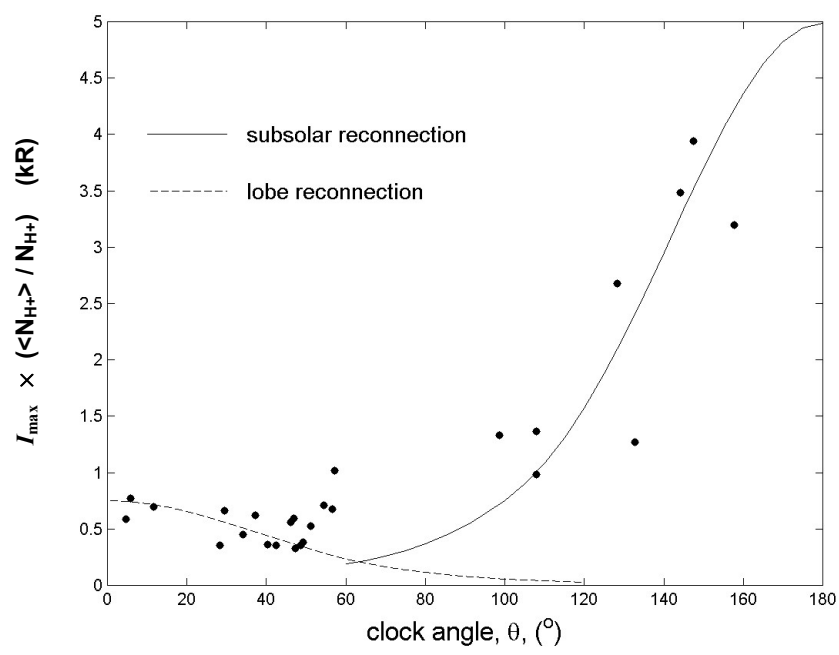

Fig. 10. Scatter plot of the normalised peak Lyman- $\alpha$ emission intensity, $I_{\max }\left\{<\mathrm{N}_{\mathrm{H}+}>/ \mathrm{N}_{\mathrm{H}+}\right\}$, where $\mathrm{N}_{\mathrm{H}+}$ is the proton data seen by $A C E$ and $\left\langle\mathrm{N}_{\mathrm{H}}\right\rangle$ is its average value over the interval 15:00-16:00. The normalised intensities are averaged over 12:0012:30 MLT and are plotted against the IMF clock angle in GSM observed by ACE, $\theta$ (points). The ACE data have been lagged by the derived ACE-to-Earth propagation delay $\delta t_{E}$. The solid line shows the variation predicted by the cusp model for a subsolar reconnection site, the dashed line is the variation predicted for the same model inputs and a lobe reconnection site.

cases, the opposite polarity of IMF $B_{y}$ would give the same behaviour, but with all dawn/dusk asymmetries reversed in sense.

In Sect. 5, we use a model to show that the Doppler-shifted Lyman- $\alpha$ proton emissions, as seen in the cusp region by the SI-12 channel of the FUV instrument on IMAGE, arose close to the reconnection $\mathrm{X}$-line on newly-opened field lines. Thus, the conditions in the magnetosheath close to the reconnection site will have been very important in determining the emission intensity that was seen. For the southward IMF case, the subsolar reconnection site results in injected solar wind plasma concentrations that are high (approximately 4 times those in the undisturbed solar wind, Spreiter et al., 1966); the temperature of the source sheath populations is similarly high (the plasma temperature is of the order of 22 times larger than that for the undisturbed solar wind ions). Motions of the reconnection site will influence the intensity of cusp emissions generated by both proton and electron precipitations, because the concentration and temperatures of the source sheath populations are functions of position. For northward IMF, the build-up of a plasma depletion layer would reduce the range of this density variation and so this effect would be smaller.

\section{Model of clock-angle dependence of cusp proton emis- sions}

Here we make use of the simulations of the emission efficiency of Doppler-shifted Lyman- $\alpha$ emission, convolved 

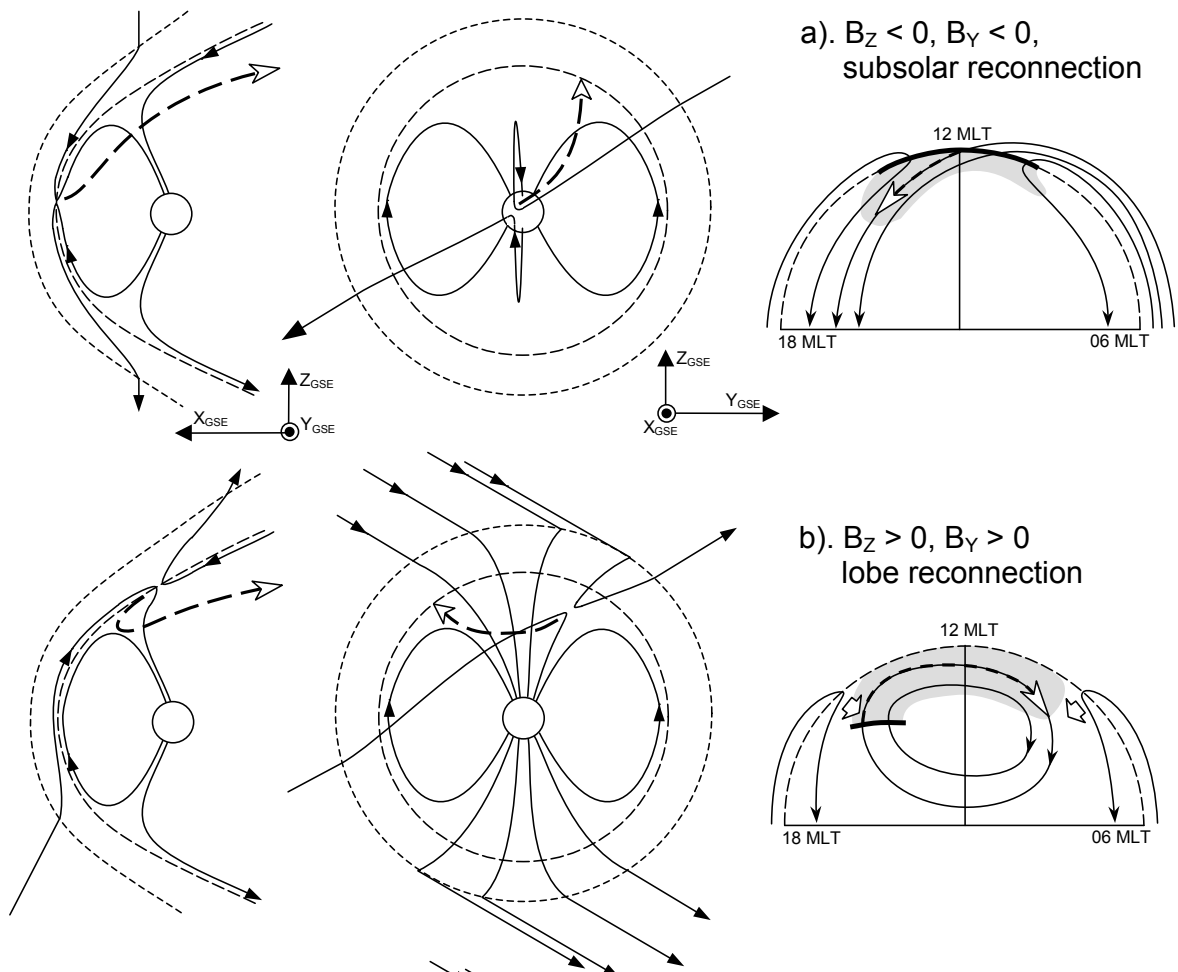

b). $B_{Z}>0, B_{Y}>0$ lobe reconnection
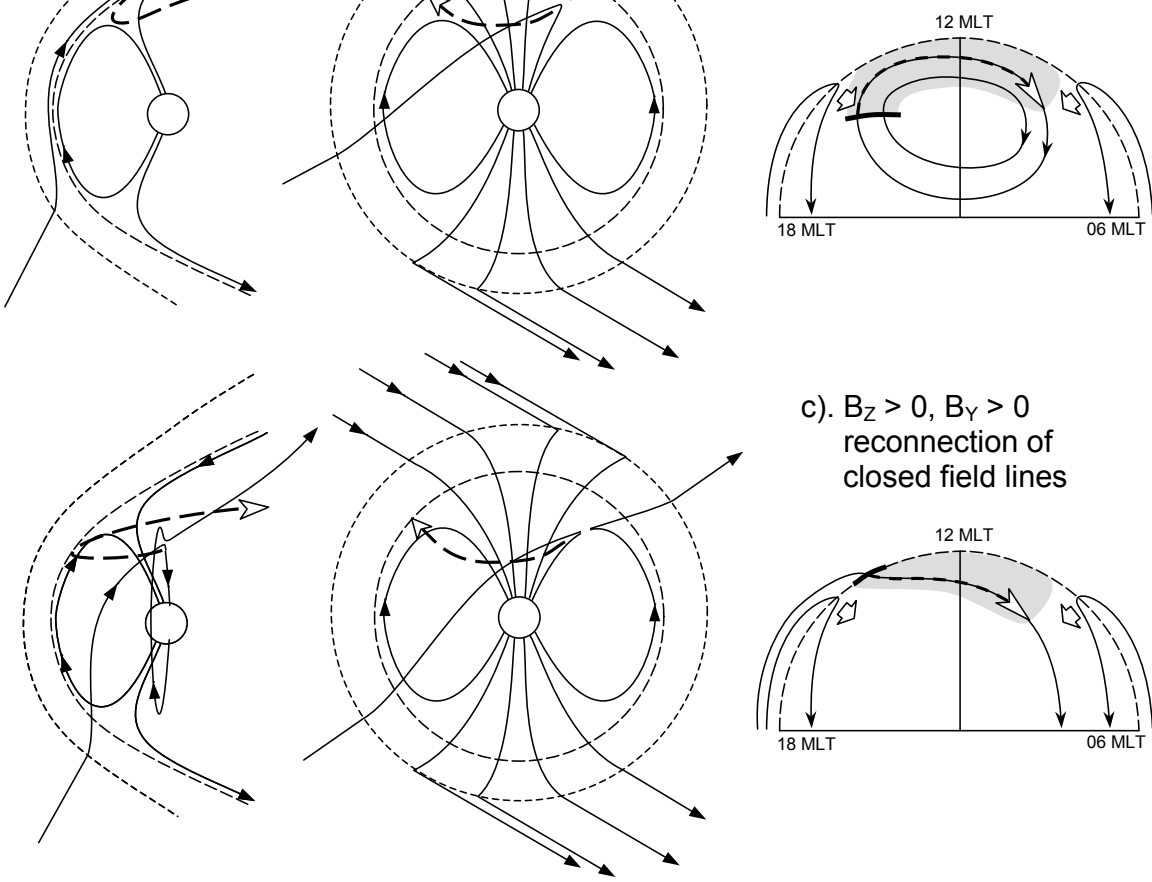

c). $B_{Z}>0, B_{Y}>0$ reconnection of closed field lines

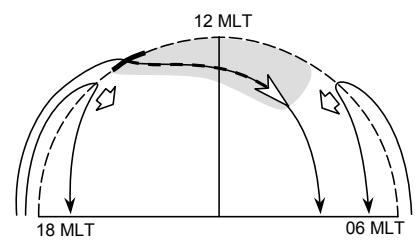

Fig. 11. Schematic illustrations of the reconnection geometry for (a) a subsolar reconnection site with IMF $B_{z}<0, B_{y}<0$, (b) a lobe reconnection site with IMF $B_{z}>0, B_{y}>0$ and (c) a dusk-flank reconnection site on closed field lines with IMF $B_{z}>0, B_{y}>0$. The left-hand figures are views of the noon-midnight meridian from the dusk flank, the centre figures are views of the dayside from the Sun; in these columns, thin lines with arrows are magnetic fields and the dashed arrow gives the evolution of newly-reconnected flux. The right-hand figures are views looking down on the northern polar cap with 12 MLT at the top of each, the grey area is newly-reconnected flux where cusp precipitation is seen. In this right-hand column, thin lines with arrows are flow streamlines, the dashed lines are non-reconnecting segments of the open-closed field line boundary (OCB), thick lines are the ionospheric projections of active reconnection sites, and open arrows show the OCB motion.

with the SI-12/FUV instrument response, made by Gérard et al. (2001). Figure 12 shows the counts, per pixel per integration time $T$, that these authors predict, as a function of the (monoenergetic) proton precipitation energy. The predictions assume nadir viewing and that the luminosity fills the pixels. Below about $3.5 \mathrm{keV}$ the instrument response falls off sharply. The decay in the number of counts per unit energy flux above $3.5 \mathrm{keV}$ is due to the fact that unit energy flux is carried by fewer particles at higher energies.

We also make use of the cusp ion precipitation model of
Lockwood and Davis (1996), in order to predict the Lyman$\alpha$ emission intensity on newly-opened field lines in the cusp region, as a function of time elapsed since the field line was reconnected. (Time elapsed since reconnection is here denoted as $\left(t_{s}-t_{o}\right)$, where $t_{s}$ is the time of observation and $t_{o}$ is the time that the field line was opened.) As discussed in Sect. 1.2, this model uses numerical gas-dynamic predictions of the plasma temperature, concentration and flow in the magnetosheath and the field line geometry at the magnetopause rotational discontinuity (RD) to predict the "Cowley- 


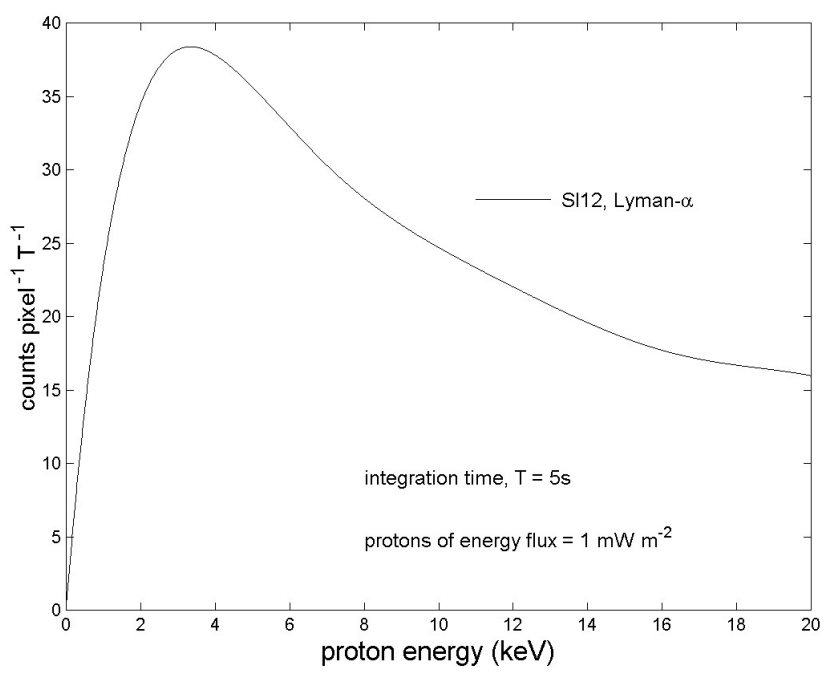

Fig. 12. The variation of the Lyman- $\alpha$ emission efficiency, convolved with the SI-12/FUV instrument response, as a function of the energy of monoenergetic precipitating protons (after Gérard et al., 2001).

D" distribution function of magnetosheath ions injected into the magnetosphere. The field-parallel portion of that distribution function reaches low altitudes where converging field lines have expanded the small pitch angle range in the losscone at the magnetopause into an almost isotropic distribution. The model accounts for the ion flight times from the magnetopause to the ionosphere along the newly-opened field lines as they convect away from the reconnection site. Thus, the model accounts for spatial structure in the magnetosheath, ion acceleration at the magnetopause RD and timeof-flight dispersion (Lockwood, 1995). Precipitation is here modelled down to an altitude of $130 \mathrm{~km}$, the lower boundary of the emission altitudes of the proton aurora.

\subsection{Generalising the cusp precipitation model for compo- nent reconnection}

Lockwood and Davis (1996) only considered the special case where the sheath field and the interior magnetospheric field were coplanar, i.e. the clock angle $\theta_{\mathrm{sh}}$ of the exterior magnetosheath field in the magnetopause $(l-m)$ plane, with respect to the interior magnetospheric field, is $180^{\circ}$. Thus these authors were simulating anti-parallel reconnection and the results were valid for component reconnection only in the special cases of purely northward or southward IMF (when the anti-parallel and component hypotheses predict the same behaviour). In this paper, we generalise to allow for other values of $\theta_{\text {sh }}$, i.e. component reconnection at general clock angles and locations. For simplicity, it is assumed that $\theta_{\mathrm{sh}}$ does not vary with $\left(t_{s}-t_{o}\right)$ as the field line evolves away from the reconnection site; this is likely to be a valid simplification as proton emission peaks at relatively small $\left(t_{s}-t_{o}\right)$.

Figure 13 shows the geometry of newly-opened field lines threading the magnetopause in magnetopause boundary- normal coordinates: $n$ is the outward boundary normal, $l$ lies in the boundary plane and is aligned with the geomagnetic meridian in the northward direction, $m$ lies in the boundary plane and makes up the right-hand set. The axes shown apply at the given location of the reconnection neutral line $\mathrm{X}$. The field inside the magnetosphere $B_{\mathrm{sp}}$ has no $m$ component, but the magnetosheath field $B_{\mathrm{sh}}$ does, making an (acute) angle $\left(\pi-\theta_{\mathrm{sh}}\right)$ with $B_{\mathrm{sp}}$ in the $l-m$ plane, as seen in Fig. 13a.

Figures $13 \mathrm{a}$ and $\mathrm{b}$ summarise our expectations for component and anti-parallel reconnection, respectively, from the discussion in Sect. 1.1. In Fig. 13a we show two orientations of the sheath field, making sheath field clock angles $\theta_{\text {sh1 }}$ and $\theta_{\mathrm{sh} 2}$ with the interior magnetospheric field at the location of the reconnection site, $\mathrm{X}$. For this component reconnection scenario, we consider the reconnection neutral line $\mathrm{X}$ to be the same in the two cases. Figure $3 b$ shows the same two sheath field orientations (in the $(l, m, n)$ frame for $\mathrm{X}$ ), but in the anti-parallel reconnection scenario, the reconnection location must be different in the two cases $\left(\mathrm{X}_{1}\right.$ and $\left.\mathrm{X}_{2}\right)$ such that the angles $\theta_{\mathrm{sh} 1}$ and $\theta_{\mathrm{sh} 2}$ are both $180^{\circ}$.

Figures $13 \mathrm{c}$ and $\mathrm{d}$ give the components of field and flow vectors for a generalised component reconnection scenario, projected onto the $l-m$ and $l-n$ planes, respectively: only when a vector lies within the plane shown is it marked with a vector symbol, otherwise it is a component in that plane. These plots show the kink in the open field line where it threads the magnetopause rotational discontinuity. Figure $13 \mathrm{~d}$ is the same basic geometry as that used by Lockwood and Davis, and as employed in the original theory of the ion acceleration by Cowley (1992); however, because the sheath field no longer lies in the $l-n$ plane, some full vectors have become components. The angles $\varepsilon$ and $\chi$ are close to zero at the reconnection site, but then increase as the open field line propagates towards the tail lobe: their values are taken to be a function of the distance from the reconnection site, using the same input variations as in the Lockwood and Davis simulations. The total flow over the boundary, $\underline{\mathrm{V}}_{\mathrm{T}}$, is the vector sum of the sheath plasma flow $\underline{\mathrm{V}}_{\text {sh }}$ and the field line velocity, $\underline{V}_{F}$ (caused by the magnetic curvature force), and is such that the field-aligned flow into the magnetopause $\mathrm{RD}$ is at the local Alfvén speed in the field line rest frame (the de Hoffman-Teller frame), as in the model of field line evolution by Cowley and Owen (1989). The kink in the field line moves with velocity $\underline{\mathrm{V}}_{\mathrm{F}}$ and this makes an angle $\delta$ with the sheath field in the $1-\mathrm{m}$ plane. From the geometric construction in the $l-m$ plane shown in Fig. 13a, the projection of the field line velocity onto the $l-n$ plane (Fig. 13d) is $\mathrm{V}_{\mathrm{F}} \cos \left(\pi-\theta_{\mathrm{sh}}-\delta\right)$. For the anti-parallel case used by Cowley and by Lockwood and Davis, this velocity was $V_{F}$. Thus, this cosine factor was unity in the Lockwood and Davis simulations (i.e. for purely southward IMF for reconnection at the nose), but here falls to zero for $\left(\theta_{\mathrm{sh}}+\delta\right)=\pi / 2$ and is negative for $\left(\theta_{\mathrm{sh}}+\delta\right)<\pi / 2$. It should be stressed here that in all cases the reconnection is at the nose of the magnetosphere and thus, the $\theta_{\mathrm{sh}} \ll \pi / 2$ cases are unlikely to be realistic because, in reality, the reconnection site will move in these northward-IMF cases to locations that give $\theta_{\mathrm{sh}} \geq \pi / 2$ 

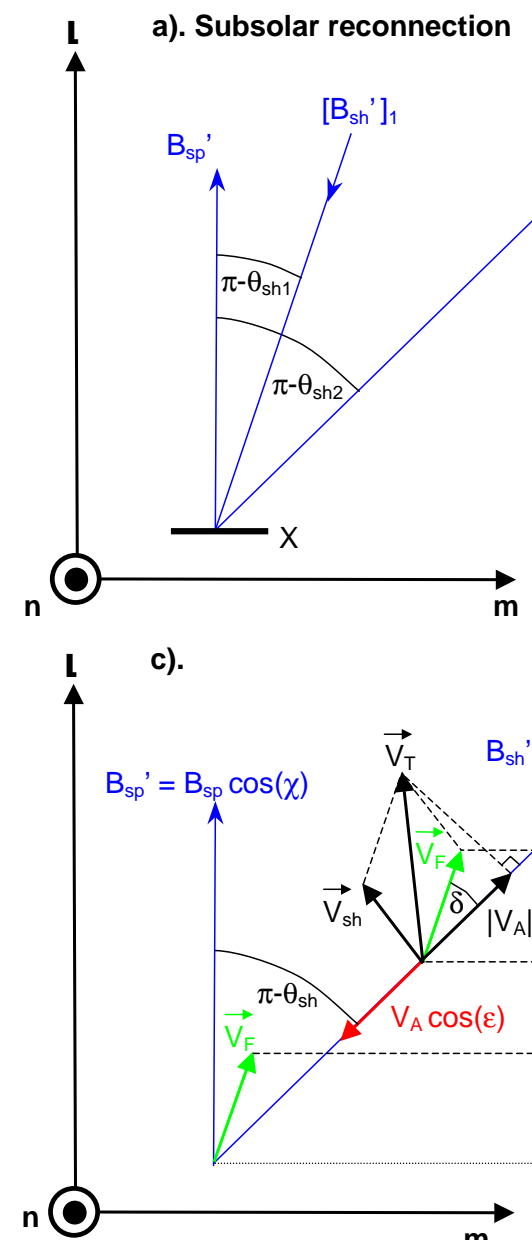

c). b). Anti-parallel reconnection

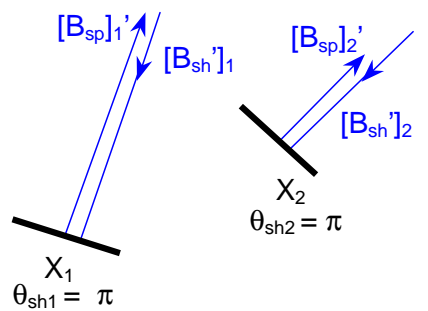

$(\mathrm{X})$

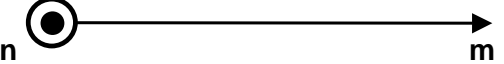

d).

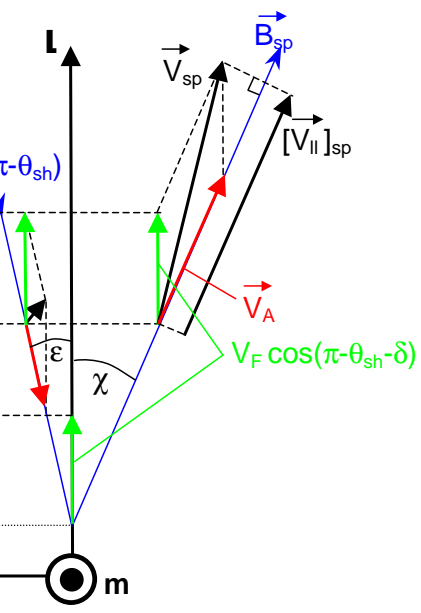

Fig. 13. Geometry of newly-opened field lines at the dayside magnetopause. (a), (b), and (c) show the $l-m$ plane of the magnetopause, whereas (d) shows a cross section of the magnetopause in the $l-n$ plane, where $\mathrm{n}$ is the outward normal to the boundary. (a) shows two orientations of the sheath field (projections onto the $l-m$ plane are $\left[B_{\mathrm{sh}}{ }^{\prime}\right]_{1}$ and $\left[B_{\mathrm{sh}}{ }^{\prime}\right]_{2}$ ) for component reconnection at a reconnection site $\mathrm{X}$. (b) shows schematically reconnection sites $\mathrm{X}_{1}$ and $\mathrm{X}_{2}$ needed to give anti-parallel reconnection for the same sheath field orientations. (c) and (d) give the geometrical construction (projected onto the $l-m$ and $n-l$ planes, respectively) needed to compute field line motion and the proton acceleration on crossing the magnetopause RD.

(as discussed in the Introduction and in Sect. 4). To compute $\underline{\mathrm{V}}_{\mathrm{F}}$, we use the sheath flow $\underline{\mathrm{V}}_{\mathrm{sh}}$ and the Alfvén speed $V_{A}$, as specified everywhere adjacent to the magnetopause by the gas-dynamic predictions. The only unknown required by the method of Cowley and Owen is then the sheath field angle $\theta_{\mathrm{sh}}$, which we prescribe here at the reconnection site and assume to remain constant over the relatively short range of elapsed time since the reconnection that we are concerned with.

The geometric construction in Fig. 13d shows how the flow of ions through the magnetopause (at the local Alfvén velocity $\mathrm{V}_{\mathrm{A}}$ in the dHT frame) adds vectorially to the field line kink velocity in the Earth's frame, $\underline{V}_{F}$, to give an ion bulk flow velocity in the Earth's frame which is considerable larger on the magnetospheric side of the boundary. Because the projection of the kink velocity into the $l-n$ plane shown in Fig. 13d, depends on the angles $\theta_{\mathrm{sh}}$ and $\delta$, the bulk flow of the accelerated ions on the magnetospheric side of the boundary $\underline{\mathrm{V}}_{\mathrm{sp}}$, and its field-aligned component $\left[\mathrm{V}_{\|}\right]_{\mathrm{sp}}$, depend on both these angles. The case studied by Lockwood and Davis employed $\theta_{\mathrm{sh}}=\delta=0$, which gives a maximum $\left[\mathrm{V}_{\|}\right]_{\mathrm{sp}}$ and smaller values will result for larger angles. Thus, the Cowley-D distribution function of injected ions is shifted to lower energies as these angles increase and the case studied by Lockwood and Davis gives peak ion acceleration at the magnetopause.

Figure 14 shows an example of the results obtained. This case is for $\theta_{\mathrm{sh}}=105^{\circ}$ and $\delta=0$, i.e. component merging with southward IMF near the nose of the magnetosphere. The simulation uses the average upstream solar wind proton concentration $\left\langle\mathrm{N}_{\mathrm{H}+}\right\rangle=2.95 \cdot 10^{7} \mathrm{~m}^{-3}$ and temperature $\left\langle\mathrm{T}_{\mathrm{H}+}\right\rangle=3.3 \cdot 10^{5} \mathrm{~K}$ observed by ACE at 14:42-14:47 UT (corresponding to 15:24-15:29 in the ionosphere), with a reconnection site that is a distance $d=5 R_{E}$ along the equato- 

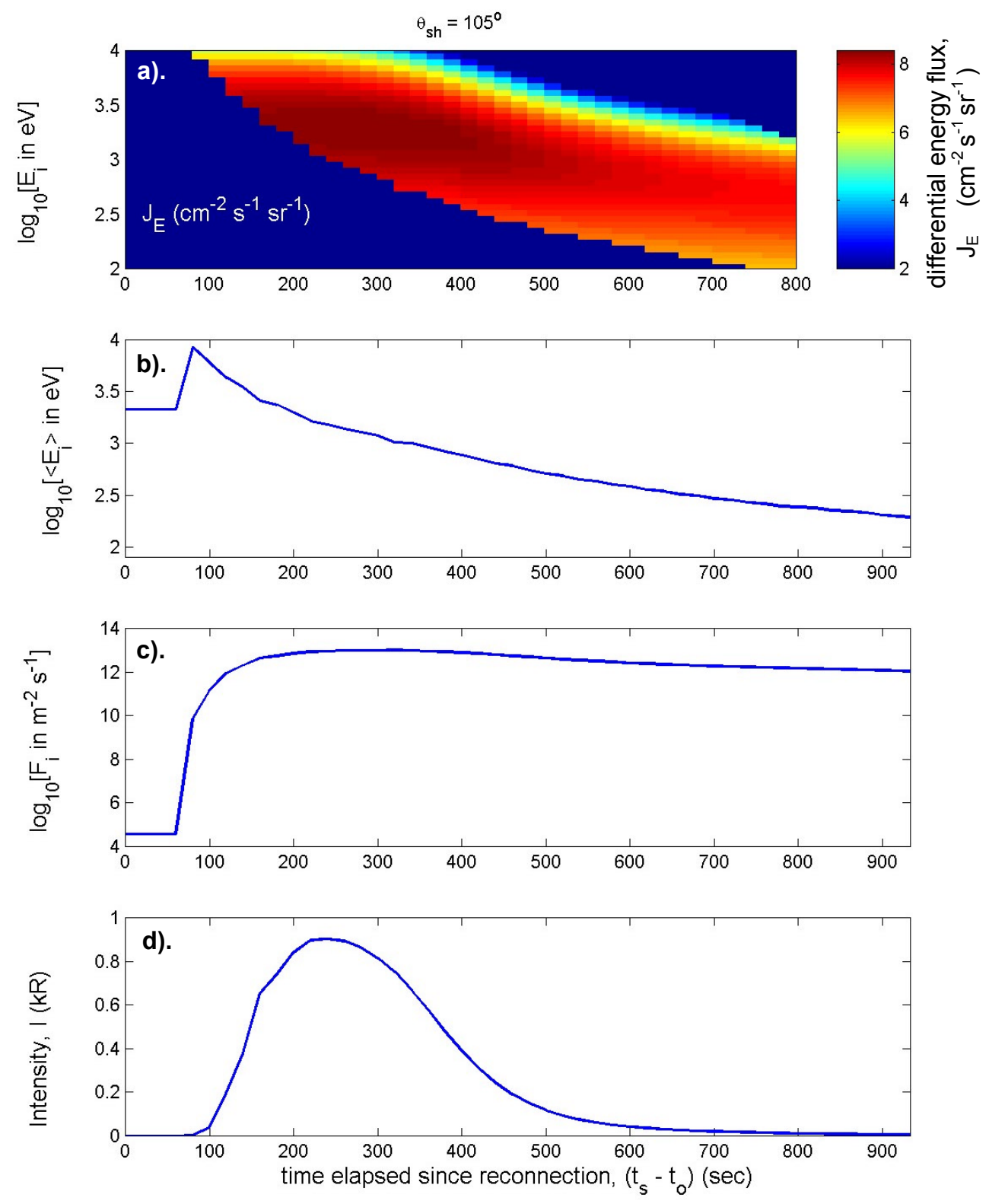

Fig. 14. Modelled cusp ions as a function of time elapsed since reconnection $\left(t_{s}-t_{o}\right)$ for a clock angle between exterior (sheath) and interior fields of $\theta_{\mathrm{sh}}=110^{\circ}$, using the model of Lockwood and Davis (1996), generalised to allow for $\theta_{\mathrm{sh}} \neq 180^{\circ}$. The simulation uses average upstream proton concentration $\left\langle\mathrm{N}_{\mathrm{H}+}\right\rangle=2.95 \cdot 10^{7} \mathrm{~m}^{-3}$ and temperature $\left\langle\mathrm{T}_{\mathrm{H}+}\right\rangle=3.3 \cdot 10^{5} \mathrm{~K}$ observed by ACE at 14:42-14:47 UT, with a near subsolar reconnection site. (a) The differential energy flux, $\mathrm{J}_{\mathrm{E}}$, colour-coded (using the scale to the right which presents $\log _{10}\left[J_{E}\right.$ in $\mathrm{cm}^{-2} \mathrm{~s}^{-1} \mathrm{sr}^{-1}$ ] and as a function of ion energy $E_{i}$ and $\left(t_{s}-t_{o}\right)$. (b) The mean ion energy $<E_{i}>$, (c) the total precipitating ion number flux $F-i$ and (d) the Lyman- $\alpha$ emission intensity, $I$, as would be detected by the SI-12/FUV instrument.

rial magnetopause from the nose of the magnetosphere. This value of $d$ was obtained by an iterative fit to the intensity observed for clock angles near $\theta_{\mathrm{IMF}}=\pi$. The top panel shows the modelled ion dispersion in spectrogram format: the differential energy flux $J_{E}$ is plotted as a function of ion energy $E_{i}$ and time elapsed since reconnection $\left(t_{s}-t_{o}\right)$. Because it shows the variation with $\left(t_{s}-t_{o}\right)$, Fig. 14 is for an imaginary observer moving with the footprint of a newly-opened field line.

The second panel of Fig. 14 shows the predicted average ion energy $\left\langle E_{i}\right\rangle$ at each $\left(t_{s}-t_{o}\right)$. This jumps up from the magnetospheric levels with the arrival of the first (highest energy) accelerated magnetosheath ions from near the reconnection site: $\left\langle E_{i}\right\rangle$ then decays with $\left(t_{s}-t_{o}\right)$ as the lower energy ions arrive (the time-of-flight effect), and because the acceleration at the magnetopause decreases with $\left(t_{s}-t_{o}\right)$. The third panel gives the downward flux of ions, $F_{i}$, which rises with the arrival of the first sheath ions and decays only slowly as the cusp precipitation, evolves into mantle precipitation because the point or particle entry for that field line is 
evolving away from the nose of the magnetosphere.

\subsection{Prediction of SI-12/FUV observations}

To estimate the Doppler-shifted Lyman- $\alpha$ emission and the SI-12/FUV instrument response to that emission, we use the results of Gérard et al. (2001) for mono-energetic precipitation, summarised in Fig. 12. We treat the modelled precipitating spectrum in Fig. 14a as the sum of a number of monoenergetic precipitations over energy ranges $d E_{i}$ wide. For each ion energy $E_{i}$, we compute the counts per second per pixel which would be produced by ions of that energy, from the total energy flux at energy in the range $E_{i}$ to $\left(E_{i}+d E_{i}\right)$ at a given elapsed time since reconnection $\left(t_{s}-t_{o}\right)$, as given by Fig. 14a. Like Gérard et al., we assume that the emission fills the pixel and that we are viewing from nadir. We then sum the total counts over all the $E_{i}$ ranges to obtain the total number of counts. These counts are then converted to kR in the same way as were the observations: namely $4.8 \mathrm{kR}$ is taken to correspond to 30 counts per pixel per 5-s integration period, which is the response simulated by Gérard et al. for a precipitating kappa spectrum of mean energy $8 \mathrm{keV}$, which represents an average for the instrument (see their Table 1).

The results for the spectra evolution presented in Fig. 14a are given in Fig. 14d. It can be seen that the modelled peak emission, in this case, occurs at $\left(t_{s}-t_{o}\right)$ near $250 \mathrm{~s}$. Before this peak, the intensity observed $I$ rises as the flux $F_{i}$ rises due to the time-of-flight effect. Note that virtually zero emission is seen for $\left(t_{s}-t_{o}\right)<150 \mathrm{~s}$ because virtually no ions have arrived at these elapsed times since reconnection. This means that the first proton emission is seen $150 V_{c}$ downstream from the actual open-closed field line boundary (OCB), where $V_{c}$ is the convection speed across the OCB. This delay is consistent with the data shown in Fig. 7: the intensity began to increase roughly $2.5 \mathrm{~min}$ after the aurora begins to migrate equatorward (when the southward turning is predicted to have reached the magnetopause). For a typical $V_{c}$ of $1 \mathrm{~km} \mathrm{~s}^{-1}$, this distance is $150 \mathrm{~km}$. After the peak, the modelled intensity $I$ decays rapidly due to the decay in the flux $F_{i}$ and, in particular, the fall in ion energies, as indicated by $\left\langle E_{i}\right\rangle$. In this case the intensity $I$ reaches a peak value, $I_{\max }$, roughly $4 \mathrm{~min}$ after the field line was reconnected.

Figure 15 shows this variation of synthesized proton emission intensity $I$ (allowing for the SI-12/FUV instrument response) with time elapsed since reconnection $\left(t_{s}-t_{o}\right)$ for a variety of model input sheath field clock angles $\theta_{\mathrm{sh}}$ (the green curve is the one discussed in detail above and shown in Fig. 14d). Two features are apparent: first, intensities are considerably enhanced when $\theta_{\mathrm{sh}}$ approaches $180^{\circ}$. This is because the larger $\theta_{\text {sh }}$ gives more acceleration at the magnetopause rotational discontinuity and this lifts more ions towards the peak in the emission efficiency curve (Fig. 12). Secondly, the time since reconnection of the peak emission increases to about $5 \mathrm{~min}$ for $\theta_{\mathrm{sh}}=180^{\circ}$ : this reflects the changing balance between the effects of ion energy and ion flux.

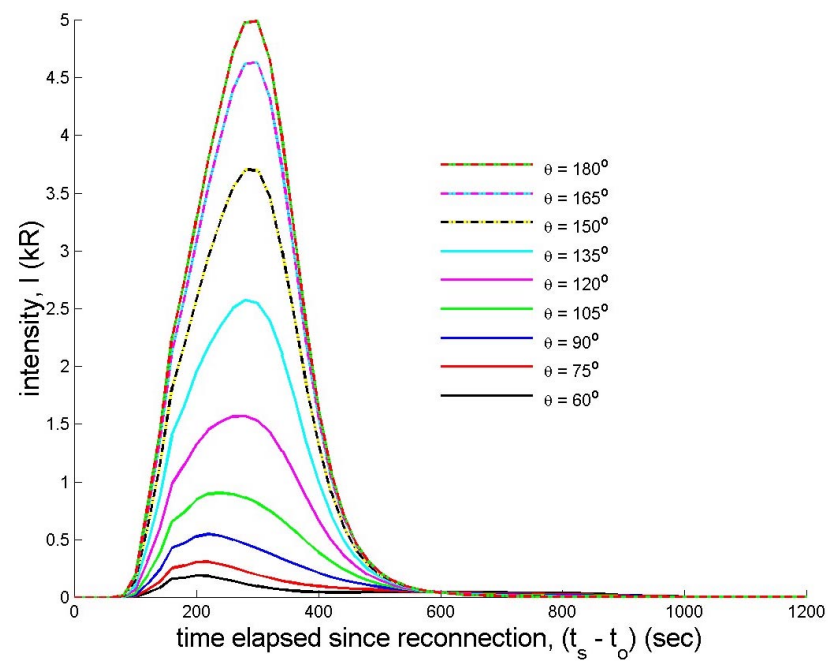

Fig. 15. Modelled variations of the Lyman- $\alpha$ emission intensity, $I$ with time elapsed since reconnection $\left(t_{s}-t_{o}\right)$ for a clock angle between exterior (sheath) and interior fields $\theta_{\mathrm{sh}}$ between $60^{\circ}$ and $180^{\circ}$.

Because we cannot readily track the ionospheric footprints of newly-opened field lines, from the IMAGE data we cannot easily or reliably reconstruct the evolution with $\left(t_{s}-t_{o}\right)$ of intensity from the data. Thus, we cannot present the observations in a way that can be compared with Figs. 14 and 15 directly. We can, however, define the peak emission and compare this with the peak intensities predicted by the model in Fig. 15.

The peak emission intensity in Fig. 15 varies from $I_{\max }=$ $0.17 \mathrm{kR}$, at $\left(t_{s}-t_{o}\right)=200 \mathrm{~s}$, for $\theta_{\mathrm{sh}}=60^{\circ}$ to $I_{\max }=4.9 \mathrm{kR}$, at $\left(t_{s}-t_{o}\right)=300 \mathrm{~s}$, for $\theta_{\mathrm{sh}}=180^{\circ}$. The full variation of the peak intensity, $I_{\max }$,with the angle $\theta_{\mathrm{sh}}$ is plotted in Fig. 10 , where it can be compared to the observed variation of peak intensity given by the points. We can compare this modelled variation of $I_{\max }$ as a function of $\theta_{\mathrm{sh}}$ with the observed $I_{\max }$ as a function of $\theta_{\mathrm{IMF}}$ because clock angle is preserved across the bow shock (e.g. Opgenoorth et al., 2001). It can be seen that the agreement for southward IMF is quantitatively good. A complication is that the IMF orientation used is for the time that the field line is predicted to have reached the reconnecting dayside magnetopause, and thus relates to $\left(t_{s}-t_{o}\right)=0$, whereas Fig. 15 shows that the Doppler-shifted Lyman- $\alpha$ emission is predicted to peak at an elapsed time since reconnection $\left(t_{s}-t_{o}\right)$ of $200 \mathrm{~s}$ for $\theta_{\mathrm{sh}}=60^{\circ}$, rising to $300 \mathrm{~s}$ for $\theta_{\mathrm{sh}}=180^{\circ}$. This additional lag of 3-5 min may cause some of the scatter in Fig. 10, having more of an effect when the IMF orientation is changing rapidly. However, we note here that the additional lag is smaller than the uncertainty in the ACE-to-Earth lag $\delta t_{E}$ caused by the unknown orientation of the IMF change front in the $[X Z]_{\mathrm{GSM}}$ plane (as discussed in Sect. 2.1, this can be considered to be typically $\pm 4 \mathrm{~min})$.

For northward IMF, Fig. 10 shows the results for a lobe reconnection site as a dashed line. The location of this 


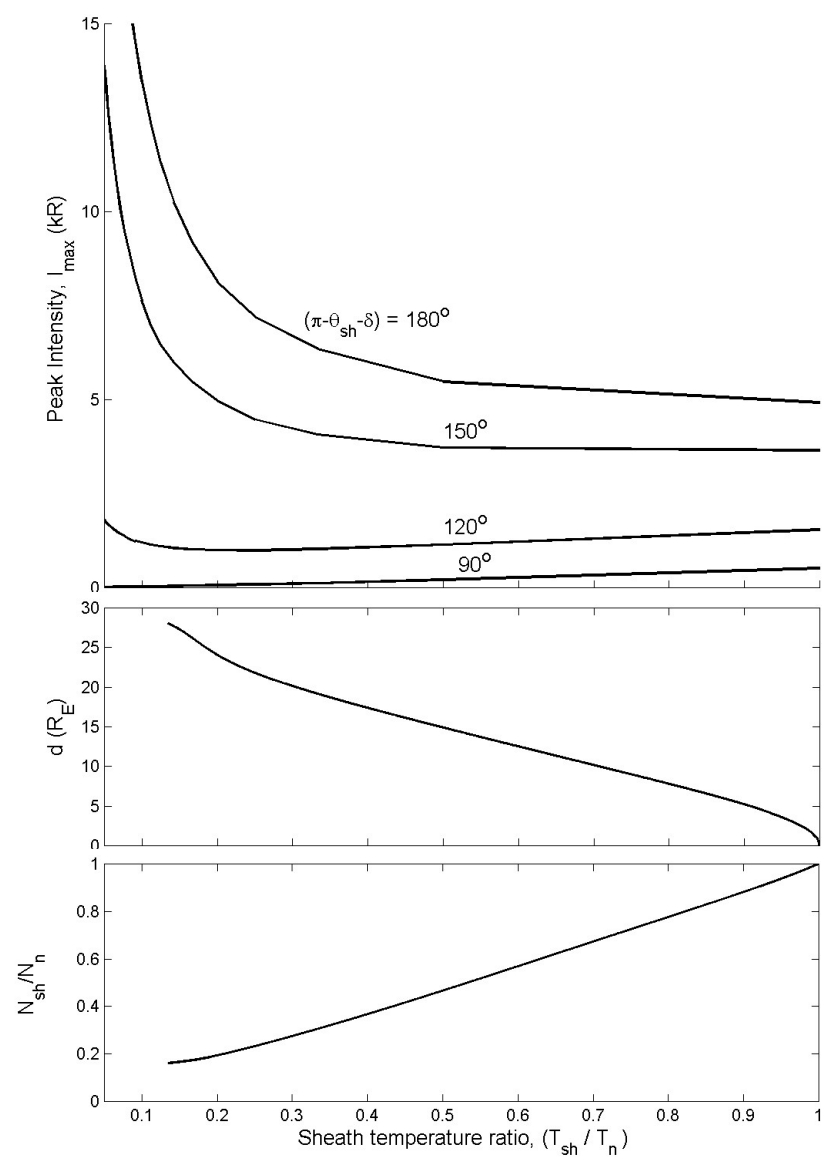

Fig. 16. (a) Modelled effect of sheath ion temperature $T_{\mathrm{sh}}$ on the peak Lyman- $\alpha$ emission. The peak emission, $I_{\max }$, is shown as a function of $T_{\mathrm{sh}} / T_{\mathrm{n}}$, where $T_{\mathrm{n}}$ is the value of $T_{\mathrm{sh}}$ at the nose of the magnetosphere $\left(T_{\mathrm{n}}=22.33 T_{\mathrm{sw}}\right)$. Values are shown for the angle factor $\left(\pi-\theta_{\mathrm{sh}}-\delta\right)$ of $180^{\circ}, 150^{\circ}, 120^{\circ}$ and $90^{\circ}$. (b) The distance from the nose of the magnetosphere, $d$, and (c) the sheath plasma concentration ratio $N_{\mathrm{sh}} / N_{\mathrm{n}}$, both as a function of $T_{\mathrm{sh}} / T_{\mathrm{n}}$, where $N_{\mathrm{n}}$ is the value of $N_{\mathrm{sh}}$ at the nose of the magnetosphere.

lobe $\mathrm{X}$-line has been chosen to match the observations near $\theta_{\mathrm{IMF}}=0$ : the value of $I_{\max }$ is lower than for the subsolar reconnection with $\theta_{\mathrm{IMF}}=180^{\circ}$, because the plasma concentration at the $\mathrm{X}$-line is lower and because the field lines convect sunward against the sheath flow, making the field line speed $V_{F}$ lower and thus reducing the ion acceleration on crossing the RD. The actual location deduced is not highly reliable because observations by the Interball and Polar satellites show that ion acceleration is indeed low for lobe reconnection, but that plasma is anomalously heated on crossing the lobe magnetopause (Savin et al., 2001; T. Phan, private communication, 2002; T. Onsager, private communication, 2002). The weak dependence of the intensity of the northward-IMF cusp on clock angle is in good agreement with the statistical survey by Frey et al. (2001): the authors found a clear dependence on solar wind concentration but a weak dependence on IMF $B_{z}$.

Figure 10 shows that the observed variation of the peak
Lyman- $\alpha$ intensity with IMF clock angle $\theta_{\mathrm{IMF}}$ over the range $90^{\circ} \leq \theta_{\mathrm{IMF}} \leq 180^{\circ}$ (southward IMF) is well explained by component near-subsolar reconnection. Similarly, the variation over the range $0^{\circ} \leq \theta_{\mathrm{IMF}} \leq 90^{\circ}$ (northward IMF) could be explained as component reconnection at a lobe reconnection site. In the next section we discuss the possibility of the anti-parallel reconnection scenario producing the same result.

\section{Interpretation in terms of component and anti- parallel reconnection}

In principle, it is possible that the reconnection site might move location even for component reconnection, and that general reconnection behaviour may be a mixture of antiparallel and component behaviours. For example, one possibility is that component reconnection is only possible relatively close to the nose of the magnetosphere where the magnetosheath flow stagnates, and that away from the nose only anti-parallel reconnection is possible.

Figure 10 demonstrates that component merging at a fixed reconnection site can explain the observed clock-angle dependence of the proton emissions revealed in this paper. It is interesting to ask if the clock angle dependence can also be explained by anti-parallel reconnection. To do this, we have to look at all the implications of the reconnection site moving - i.e. of there being systematic variations with the clock angle $\theta_{\mathrm{IMF}}$ of the distance $d$ in the magnetopause surface between the reconnection site and the nose of the magnetosphere. Table 1 lists all the relevant factors for a decrease in the IMF clock angle $\theta_{\mathrm{IMF}}$ from its peak value of $\pi$ to smaller values. The cusp auroral measurements discussed in the Introduction suggest that $\theta_{\mathrm{sh}}$ must exceed about $\pi / 4$ before low-latitude component reconnection can occur. In addition, the angle $\delta$ has a maximum limit of $\pi / 2$, because larger values would mean that reconnected field lines were moving back into the reconnection site and reconnection could not be sustained.

6.1 Magnetosheath electron and ion concentration changes at the reconnection site

The plasma concentration in the magnetosheath $N_{\text {sh }}$, close to the magnetopause boundary, is a function of position. The gas-dynamic models predict that the ratio $N_{\mathrm{sh}} / N_{\mathrm{sw}}$ (where $N_{\text {sw }}$ is the plasma concentration in the undisturbed solar wind) is about 4.2 at the nose of the magnetosphere, but this ratio falls to values below 1 at large $d$ (above about $20 R_{E}$ ). Moving the reconnection site will change the concentration of plasma entering the low-latitude edge of the cusp and thus precipitating into the ionosphere down newly-opened field lines close to the open-closed field line boundary. Burch (1985) has shown that quasi-neutrality of plasma holds in the cusp and thus, this effect will influence the electron and ion precipitation flux by the same factor. This is inconsistent with the observations presented here, as it would mean that 
Table 1. Effect of decreasing IMF clock angle $\theta_{\mathrm{IMF}}$ from $\pi$

\begin{tabular}{lll}
\hline & Component Merging & Anti-parallel Merging \\
\hline X-line location & considered here as fixed & must move away from nose \\
Distance from nose, $d$ & stays constant & increases \\
Sheath proton concentration at X-line & stays constant & decreases \\
Sheath electron concentration at X-line & stays constant & decreases by same amount \\
& & $\begin{array}{l}\text { as proton concentration } \\
\text { decreases }\end{array}$ \\
Sheath proton temperature at X-line & stays constant & likely to decrease, \\
Sheath electron temperature at X-line & stays constant & but not as much as ion temperature \\
& constant at $\pi$ \\
Sheath field clock angle, $\theta_{\mathrm{sh}}$ & decreases (down to limit & \\
of about $\pi / 4)$ & increases (up to limit of $\pi / 2)$ & increases (up to limit $\pi / 2)$ \\
Sheath flow angle, $\delta$ & decreases & decreases \\
cos $\left(\pi-\theta_{\text {sh }}-\delta\right)$ factor & approximately constant & Flow orientation effect causes decrease \\
Field line velocity, $\mathrm{V}_{\mathrm{F}}$ & & Flow magnitude effect causes increase \\
\hline
\end{tabular}

changes in the OI oxygen emission would match those in the Lyman- $\alpha$, such that the ratio of the two is constant. Figure $8 b$ shows that this is not the case. Furthermore, the predicted dayside plasma concentration variation in the magnetosheath is by a factor of about 4 at most, and thus, this is smaller than the observed variation, which was by a factor of about 6. An additional complication is that a build-up of magnetic pressure in a PDL also decreases $N_{\text {sh }}$; however, this reduction is predominantly at the nose of the magnetosphere where draped field lines are hung up on the magnetosphere. This means that the range of $N_{\mathrm{sh}}$ values in the sheath is reduced below the factor 4.2 predicted by the gas-dynamic model. We can conclude that, although a relevant influence, plasma concentration changes caused by motion of the reconnection site is not sufficient as an explanation of the clock-angle dependence of the proton emission intensities reported in this paper.

6.2 Magnetosheath electron and ion temperature changes at the reconnection site

Plasma temperature gradients in the magnetosheath are greater than the corresponding plasma concentration gradients. The gas-dynamic models predict that at the nose of the magnetosphere the plasma temperature is 22.3 higher than the plasma temperature in the undisturbed solar wind, and that this factor decreases towards unity with increasing $d$. However, the behaviour of the ion and electron temperatures is likely to be different. Very little systematic information is available on this; however, electron temperature is expected to be somewhat more constant than ion temperature due to electron heating at the bow shock and the greater electron mobility.

Figure 16 studies the effect of sheath ion temperature $T_{\mathrm{sh}}$ on the peak proton emission intensity, using the model de- scribed in Sect. 5. In the top panel, the peak emission $I_{\max }$ is plotted as a function of the ratio $T_{\mathrm{sh}} / T_{\mathrm{n}}$, where $T_{\mathrm{n}}$ is the value of $T_{\mathrm{sh}}$ at the nose of the magnetosphere $(d=0)$. To place the range of sheath temperature changes modelled into context, parts (b) and (c) of Fig. 16 show the gas-dynamic predictions of the corresponding $d$ and the ratio $N_{\mathrm{sh}} / N_{\mathrm{n}}$ (where $N_{\mathrm{n}}$ is the value of the sheath concentration at the magnetopause, $N_{\text {sh }}$, at $d=0$ ). In order to isolate the effect of temperature, the plasma concentration at the X-line is held constant in Fig. 16a. The results are found to depend on the degree of ion acceleration at the rotational discontinuity, which is modified by both the sheath field clock angle $\theta_{\text {sh }}$ and the field line motion angle $\delta$ (see Fig. 13c). Figure 16 shows the results for $\left(\pi-\theta_{\mathrm{sh}}-\delta\right)$ of $180^{\circ}, 150^{\circ}, 120^{\circ}$ and $90^{\circ}$. The effect of sheath temperature is different in these cases. For low $\left(\pi-\theta_{\mathrm{sh}}-\delta\right)$, the ion acceleration at the magnetopause is low. In these cases, decreasing $T_{\text {sh }}$ (by increasing $d$ ) causes there to be fewer ions in the hot tail in the ion distribution and these are the only ions with sufficient energy to cause significant counts in the SI-12/FUV instrument (see Fig. 12). Thus, $I_{\max }$ decreases with decreasing $T_{\text {sh }}$ (increasing $d$ ) for small $\left(\pi-\theta_{\mathrm{sh}}-\delta\right)$. On the other hand, for high $\left(\pi-\theta_{\mathrm{sh}}-\delta\right)$ the ion acceleration at the magnetopause is large. Consequently, the hot tail of the ion distribution is at energies considerably greater than the energy of peak response in Fig. 12. Thus, in these cases, reducing $T_{\text {sh }}$ causes more ions to be at the energy of peak instrument response and the number of instrument counts increases. Thus, $I_{\max }$ increases with decreasing $T_{\text {sh }}$ (increasing $d$ ) for large $\left(\pi-\theta_{\mathrm{sh}}-\delta\right)$.

However, Fig. 16 shows that these changes in $I_{\max }$ caused by magnetosheath ion temperature changes are relatively small (compared to the changes caused by ion concentration variations and the magnetopause acceleration factor), except for unrealistically large $d$ (greater than about $20 R_{E}$ ) and $\left(\theta_{\text {sh }}+\delta\right)$ near zero. Thus, we expect the relatively small 
effects because the X-line usually remains within $20 R_{E}$ of the nose.

\subsection{Magnetosheath field clock angle and magnetosheath flow angle}

By definition, the clock angle that the sheath field makes with the interior field at the $\mathrm{X}$-line, $\theta_{\mathrm{sh}}$, is $\pi$ for anti-parallel merging. However, moving the reconnection site also alters the orientation of the sheath flow with the sheath field and this changes the angle $\delta$ which the field line velocity makes with the sheath field (as defined by Fig. 13). The angle $\delta$ has a maximum value of $\pi / 2$ : for greater $\delta$ the newly-reconnected field lines would be moving back toward the X-line and reconnection could not be sustained. Thus, $\delta$ is constrained to be between 0 and $\pi / 2$. If we consider that the realistic range of $\theta_{\mathrm{sh}}$ values for component merging is from near $\pi / 4$ to $\pi$, we can see that anti-parallel reconnection, through the angle $\delta$, can introduce a similar variation into the factor $\cos \left(\pi-\theta_{\mathrm{sh}}-\delta\right)$ as can component reconnection.

\section{Discussion and conclusions}

We have presented observations of the response of the dayside ionosphere to changes in the IMF clock angle. Specifically, we have looked at the changes in the Lyman- $\alpha$ proton aurora, the oxygen OI emissions and the pattern of dayside convection.

\subsection{The response of dayside aurora and ionospheric flow}

The data presented here provide a good demonstration of the model of ionospheric flow excitation by Cowley and Lockwood (1992). The high solar wind concentration during this event allowed the production of newly-opened flux to be monitored by the FUV/SI-12 instrument on IMAGE, using the proton aurora produced by magnetosheath ions precipitating into the cusp ionosphere. Figure 7 shows that a number of things happened when the effects of the onset of the increase in IMF clock angle reached the ionosphere (estimated to be at 15:19 UT). Specifically, the aurora (seen in both Lyman- $\alpha$ proton and oxygen OI emissions) began to migrate equatorward near noon and the proton aurora began to intensify roughly $2.5 \mathrm{~min}$ later. Shortly thereafter, the convection flows began to increase (as quantified by in the transpolar voltage $\Phi_{\mathrm{pc}}$ ). Figure 4 shows that intially the brightening of the cusp proton aurora was restricted to a spot near noon but that this grew in longitude and eroded equatorward over about $3 \mathrm{~h}$ of MLT during the interval (15:19-15:27 UT). The model presented in Sect. 5 (see Fig. 15) predicts that the proton emission peaks on each newly-opened field line $3 \mathrm{~min}$ after reconnection for smaller clock angles (appropriate to the onset), rising to $5 \mathrm{~min}$ for larger clock angles (appropriate to the peak of the variation of Lyman- $\alpha$ emission). Much of this delay is due to the flight time of cusp ions from the magnetopause to the ionosphere. Thus, we can conclude that the reconnection causing the initial erosion mainly occurred at 15:16-15:22. On the other hand, the ionospheric transpolar voltage first rises at 15:22 and did not peak until 15:37. Thus, the flow lags behind the reconnection, as predicted by the Cowley-Lockwood model and is inconsistent with the concept of spatial mapping of the reconnection electric field into the ionosphere. The relatively rapid response of the proton aurora allows us to image the area of newly-opened flux generated by a reconnection pulse in this case (and because solar wind concentrations were sufficiently high); Figure (4) shows that it has the form envisaged by Cowley and Lockwood (1992).

Following the second peak in the proton emission, caused by the second peak in the IMF clock angle, the luminosity on the newly-opened field lines faded over the interval 15:3615:43. This is consistent with the model predictions of the cusp proton aurora which show that emission will decay at elapsed times since reconnection $\left(t_{s}-t_{o}\right)$ between about 4 and 9 min (Fig. 15). Figure 4 shows that the dayside aurora was returning to a more circular form at this time, as was also predicted by the Cowley-Lockwood flow excitation model. After 15:39, when the IMF returned to small clock angles, the dayside aurora migrated poleward (Fig. 7e) and poleward convection is maintained (the transpolar voltage $\Phi_{\mathrm{pc}}$ remains at $50-80 \mathrm{kV}$, Fig. $7 \mathrm{~d}$ ). The convection and auroral boundary velocities were similar at this time. Both signatures are consistent with the poleward retreat of the now non-reconnecting (i.e. adiaroic) polar cap boundary following the return of the IMF to small clock angles. Thus, the observed convection flow response was fully consistent with the Cowley-Lockwood model, as was the erosion and relaxation of the dayside open-closed field line boundary, approximately delineated by the equatorward edge of the cusp proton emission.

Another feature predicted by the Cowley-Lockwood model is the expansion of the convection pattern, consistent with several sets of observations, as discussed in Sect. 1.5. This expansion can arise for three reasons: the first is due to any longitudinal expansion of the active merging gap, as postulated by Lockwood et al. (1993), Lockwood (1994), Milan et al. (2000a), and McWilliams et al. (2001). Secondly, expansion will be caused by the fact that newly-opened flux is eroded from the dayside and only later added to the geomagnetic tail by the solar wind flow (Cowley and Lockwood, 1992): this makes those segments of the open-closed boundary that are expanding equatorward evolve towards midnight as the newly-opened flux in the lobe propagates antisunward (Lockwood, 2002). In the case presented here, the time constant for doing this will have been roughly two-thirds of the typical values (i.e. of the of order 10 min instead of the typical $15 \mathrm{~min}$ ) because the solar wind speed is of the order of $600 \mathrm{~km} \mathrm{~s}^{-1}$ (which is 1.6 times larger than the mode value of the solar wind speed of $370 \mathrm{~km} \mathrm{~s}^{-1}$ ). Thirdly, even if the polar cap expands uniformly at all MLT and the convection pattern is constant in form, the dominance of dayside reconnection in this growth phase means that there are gradients in flow speeds that will mean that equipotentials will migrate away from noon as the polar cap voltage increases and flows 
a). $15: 30-15: 32 \mathrm{UT}$

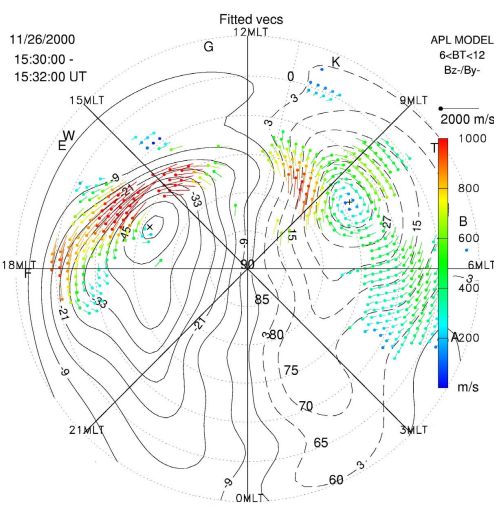

b). $15: 42-15: 44 \mathrm{UT}$

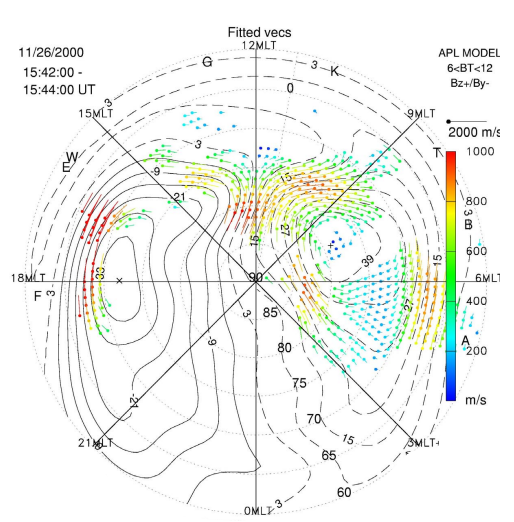

C). $15: 46-15: 48 \mathrm{UT}$

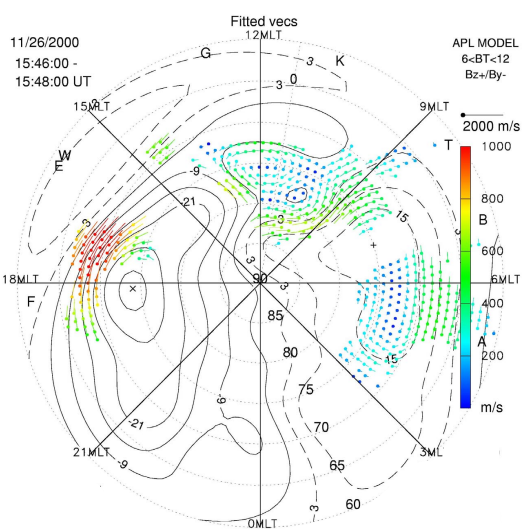

Fig. 17. (a) Fitted model convection patterns and flow vectors (one component of which is observed and the other component, perpendicular to the line-of-sight, is generated from the model fit) from SuperDARN radar data integrated over (a) 15:30:00-15:32:00 UT; (b) 15:42:0015:44:00 UT and (c) 15:46:00-15:48:00 UT. Flow vectors are color-coded according to their magnitude.

intensify (Lockwood and Cowley, 1999).

At first sight, the flow patterns shown in Fig. 4 do not appear to show the expansion of the convection pattern predicted by the Cowley-Lockwood model. However, it is important to note that these flow patterns are derived using a model fit to the SuperDARN data. The model used is a function of the lagged IMF, with no allowance for the history of the IMF: in other words, the model assumes steady state and fits steady-state flow patterns and will thus tend to suppress features that are associated with the expansion, which is a non-steady-state feature. This is important because the availability of radar data was not uniform: in particular, coverage was poorest in the pre-midnight sector at this UT and thus, this sector of the flow pattern derived is the most dependent on the (steady-state) model.

That having been said, expansion can be seen where the model fit is most informed by radar data, namely in the dawn flow cell. The MLT segment where flow is equatorward (giving streamlines that cross the open-closed boundary, out of the polar cap) can be seen to migrate away from noon, being at 5-8 MLT at 15:31:40 UT, 1-6 MLT at 15:41:53 UT and 04 MLT at 15:48:02 UT. This can be seen in greater detail in Fig. 17, which shows the fitted equipotentials and vectors from the observations. The vectors are fits to observed lineof-sight flow components. An additional indicator of the expansion is the flow "throat" into the polar cap that can be seen to have expanded from 11-14 MLT at 15:25:32, to 9-16 MLT at 15:33:43 UT.

\subsection{Open field line production during northward IMF}

The observed IMF clock angle dependence of dayside flows and the cusp proton aurora in this event provides evidence that opening of closed flux can continue even when the IMF points northward, provided that the clock angle is not too small. Several authors have reported satellite observations showing that reconnection can take place between the cusps (producing new open flux) when the IMF is northward, for $\theta_{\mathrm{IMF}}$ between $\pi / 2$ and about $\pi / 4$ (Onsager and Fuselier, 1994; Fuselier et al., 1995; Chandler et al., 1999), although some of these cases can also be interpreted as lobe reconnection (Onsager et al., 2001). Two bands of cusp red-line aurora $(630 \mathrm{~nm})$ are often seen for $\pi / 4<\theta_{\mathrm{IMF}}<\pi / 2$ (Sandholt et al., 1998) and this is interpreted as reconnection taking place simultaneously at the lobe magnetopause and "low-latitudes" (meaning between the cusps). This signature has also been defined in EISCAT radar data (McCrea et al., 2000) and satellite observations of the cusp (Weiss et al., 1995). Anderson et al. (1997) have suggested an explanation of of the production of new open field lines for northward IMF in terms of the sheath field distortion in the plasma depletion layer. Figure 7 demonstrates that erosion did indeed occur for $\pi / 4<\theta_{\mathrm{IMF}}<\pi / 2$ : the equatorward erosion commenced at 15:19, but the lagged IMF did not turn southward $\left(\theta_{\mathrm{IMF}}>\pi / 2\right)$ until 15:23, when both the transpolar voltage and the peak proton aurora intensity increased steeply. The northward turning was sufficiently sudden that $\theta_{\mathrm{IMF}}$ fell below both $\pi / 4$ and $\pi / 2$ at approximately the same time (15:39, when equatorward motion of the aurora ceases) and this effect was, therefore, not detectable during the northward turning.

\subsection{Differentiating between component and anti-parallel reconnection}

The data presented here clearly show a modulation of the intensity of cusp proton emission with IMF clock angle. We have combined a model of cusp ion precipitation by Lockwood and Davis (1996) and Lockwood (1997b) with theoretical considerations of the excitation of Lyman- $\alpha$ emissions, convolved with the IMAGE SI-12/FUV imager response. This model has been generalised to allow for variations in the clock angle $\theta_{\mathrm{sh}}$ of the sheath field (with respect to the internal field) at the reconnection site, and the angle $\delta$ of the direction 
of motion of the newly-opened field lines (with respect to the sheath field direction). We have shown that the proton emission intensity is strongly modulated by the ion acceleration, giving a dependence on the factor $\cos \left(\pi-\theta_{\mathrm{sh}}-\delta\right)$. Component reconnection will modulate the Lyman- $\alpha$ intensity via the angle $\theta_{\mathrm{sh}}$. For anti-parallel reconnection, on the other hand, $\theta_{\mathrm{sh}}$ is constant at $\pi$ by definition; however, the angle $\delta$ can generate a similar variation in the ion acceleration. Thus, discriminating between the two reconnection scenarios is not straightforward.

In this paper, we have reproduced the observed variation of the Lyman- $\alpha$ intensity with the IMF clock angle $\theta_{\mathrm{IMF}}$, by changing only the sheath field clock angle $\theta_{\text {sh }}$, with all other variables fixed. Thus, we have demonstrated that the data can be explained as component reconnection at a fixed reconnection site.

Evaluating whether anti-parallel reconnection could have produced a similar variation is much more difficult. Because anti-parallel and component reconnection are equivalent for $\theta_{\mathrm{IMF}}$ of 0 and $\pi$, it is the variations at intermediate $\theta_{\text {IMF }}$ which will distinguish the two. For the anti-parallel case, the sheath field clock angle $\theta_{\mathrm{sh}}$ is constant, but the sheath ion temperature $T_{\mathrm{sh}}$ and concentration $N_{\mathrm{sh}}$, as well as the field line speed $V_{F}$ and direction angle $\delta$ all change for newly-opened field lines, because the reconnection site changes. We have shown that the effect of the sheath temperature variation is small. Modelling the variations of the reconnection location (and hence, of $N_{\mathrm{sh}}, V_{F}$ and $\delta$ ) with IMF clock angle $\theta_{\mathrm{IMF}}$ in a self-consistent manner requires a global MHD model of the magnetosphere (with reconnection induced, where $\theta_{\mathrm{sh}}=\pi$ ) and is beyond the scope of the present paper.

However, a potential test from observations may be made possible by careful analysis of multiwavelength observations of the cusp aurora. In the case of anti-parallel reconnection, the variations in ion acceleration must necessarily be accompanied by variations in the sheath plasma concentration at the X-line and thus, in the flux of both the electron and ion precipitations. Therefore it becomes important to understand the fractions of the oxygen OI emission that are excited by primary electron precipitation and by secondary electrons produced by the proton precipitation. In a subsequent paper we will study the variations of the Doppler-shifted Lyman$\alpha$ emission and the oxygen OI emissions to see if there is evidence for changes in both the ion and the electron primary precipitation fluxes associated with the ion acceleration change (such as would be expected for anti-parallel reconnection) or whether these fluxes are constant and the intensity variations are explained by variations in the ion acceleration alone with no associated number flux changes (which would reveal component reconnection).

Acknowledgements. The authors are grateful to Dr. Ron P. Lepping (NASA/Goddard SFC) and the MFI team for provision of the IMF data from Wind, to Prof. Norman F. Ness (Bartol Research Institute) and the MAG team for provision of the ACE IMF data and Dr David J. McComas (LANL) and the SWEPAM team for provision of the ACE solar wind data. The CUTLASS SuperDARN radar and the work of ML and SM is funded by the UK Particle Physics and Astronomy Research Council. KT is grateful to Southampton University for a PhD studentship.

Topical Editor G. Chanteur thanks A. Fedorov and L. Zelenyi for their help in evaluating this paper.

\section{References}

Ahn, B.-H., Kamide, Y., Kroehl, H. W., and Gorney, D. J.: Crosspolar potential difference, auroral electrojet indices, and solar wind parameters, J. Geophys. Res., 97, 1345-1352, 1992.

Anderson, B. J., Phan, T. D., and Fuselier, S. A.: Relationships between plasma depletion and subsolar reconnection, J. Geophys. Res., 102, 9531-9542, 1997.

Arnoldy, R. L.: Signature in the interplanetary medium for substorms, J. Geophys. Res., 76, 5189, 1971.

Aubry, M. P., Russell, C. T., and Kivelson, M. G.: Inward motion of the magnetopause before a substorm, J. Geophys. Res., 75, 7018, 1970.

Banks, P. M., Araki, T., Clauer, C. R., St-Maurice, J. P., and Foster, J. C.: The interplanetary magnetic field, cleft currents, and plasma convection in the polar caps, Planet. Space Sci., 32, 1551-1560, 1984.

Berchem, J. and Russell, C. T.: Flux transfer events on the magnetopause: Spatial distribution and controlling factors, J. Geophys. Res., 89, 6689-6703, 1984.

Boyle, C. B., Reiff, P. H., and Hairston, M. R.: Empirical polar cap potentials, J. Geophys. Res., 102, 111-125, 1997.

Burch, J. L.: Rate of erosion of dayside magnetic flux based on a quantitative study of polar cusp latitude on the interplanetary magnetic field, Radio Sci., 8, 955-961, 1973.

Burch, J. L.: Quasi-neutrality in the polar cusp, Geophys. Res. Lett., 12, 469-472, 1985.

Burch, J. L, Reiff, P. H., Heelis, R. A., Winningham, J. D., Hanson, W. B., Gurgiolo, C., Menietti, J. D., Hoffman, R. A., and Barfield, J. N.: Plasma injection and transport in the mid-altitude polar cusp, Geophys. Res. Lett., 9, 921-924, 1982.

Carbary, J. F. and Meng, C.-I.: Correlation of cusp width with $\mathrm{AE}(12)$ and $B_{z}$, Planet. Space Sci., 36, 157-161, 1988.

Chandler, M. O., Fuselier, S. A., Lockwood, M., and Moore, T. E.: Evidence of component magnetic merging equatorward of the cusp , J. Geophys. Res., 104, 22 623-22 648, 1999.

Chisham, G., Pinnock, M., Coleman, I. J., Hairston, M. R., and Walker, A. D. M.: An unusual geometry of the ionospheric signature of the cusp: implications for magnetopause merging sites, Ann. Geophysicae, 20, 29-40, 2002.

Clauer, C. R. and Banks, P. M.: Relationship of interplanetary electric field to the high latitude ionospheric electric field and currents: observations and model simulation, J. Geophys. Res., 93, 2749-2754, 1988.

Coleman, I. J., Pinnock, M., and Rodger, A. S.: The ionospheric footprint of anti-parallel merging regions on the dayside magnetopause, Ann. Geophysicae, 18, 511-516, 2000.

Coleman, I. J., Chisham, G., Pinnock, M., and Freeman, M. P.: An ionospheric convection signature of anti-parallel reconnection, $\mathrm{J}$. Geophys. Res., 106, 28 995-29008, 2001.

Cooling, B. M. A., Owen, C. J., and Schwartz, S. J.: The Role of the Magnetosheath Flow in Determining the Motion of Open Flux Tubes, J. Geophys. Res., 106, 18 763, 2001.

Coroniti, F. V. and Kennel, C. F.: Can the ionosphere regulate magnetospheric convection?, J. Geophys. Res., 78, 2837-2851, 1973. 
Cowley, S. W. H.: Magnetospheric and ionospheric flow and the interplanetary magnetic field, in Physical basis of the Ionosphere in the Solar-Terrestrial System, AGARD CP-295, pp. 4/1-4/14, 1981.

Cowley, S. W. H.: The causes of convection in the Earth's magnetosphere: A review of developments during IMS, Rev. Geophys., 20, 531-565, 1982.

Cowley, S. W. H.: Evidence for the occurrence and importance of reconnection between the Earth's magnetic field and the interplanetary magnetic field, in: Magnetic reconnection in space and laboratory plasmas, (Ed) Hones, Jr., E. W., pp. 375-378, Geophysical monograph 30, American Geophysical Union, Washington DC, 1984a.

Cowley, S. W. H.: Solar wind control of magnetospheric convection, in Achievements of the international magnetospheric study, IMS, pp483-494, ESA SP-217, ESTEC, Noordwijk, The Netherlands, 1984b.

Cowley, S. W. H. and Owen, C. J.: A simple illustrative model of open flux tube motion over the dayside magnetopause, Planet. Space Sci., 37, 1461, 1989.

Cowley, S. W. H. and Lockwood, M.: Excitation and decay of solar-wind driven flows in the magnetosphere-ionosphere system, Ann. Geophysicae, 10, 103-115, 1992.

Cowley, S. W. H., Khan, H., and Stockton-Chalk, A.: Plasma flow in the coupled magnetosphere-ionosphere system and its relationship to the substorm cycle, in: "Substorms 4", (Eds) Kokubun, S. and Kamide, Y., Terra. Sci, Tokyo, pp. 623-628, 1998

Cowley, S. W. H., Morelli, J. P., and Lockwood, M.: Dependence of convective flows and particle precipitation in the high-latitude dayside ionosphere on the $X$ and $Y$ components of the interplanetary magnetic field, J. Geophys. Res., 96, 5557-5564, 1991.

Crooker, N. U.: Dayside merging and cusp geometry, J. Geophys. Res., 84, 951, 1979.

Crooker, N. U.: Reverse convection, J. Geophys. Res., 97, 19363 19372, 1992.

Crooker, N. U. and Rich, F. J.: Lobe cell convection as a summer phenomenon, J. Geophys. Res., 98, 13 403-13 407, 1993.

Crooker, N. U., Toffoletto, F., and Gusenhoven, M. S.: Opening the cusp, J. Geophys. Res., 96, 3497-3503, 1991.

Daly, P. W., Saunders, M. A., Rijnbeek, R. P., Sckopke, N., and Russell, C. T.: The distribution of reconnection geometry in flux transfer events using energetic ion, plasma and magnetic data, J. Geophys. Res., 89, 3843, 1984.

Davis, C. J., Wild, M. N., Lockwood, M., and Tulunay, Y. K.: Ionospheric and geomagnetic response to changes in IMF $B_{Z}$ : a super-posed epoch study, Ann. Geophysicae, 15 , 217-230, 1997.

Doyle, M. A. and Burke, W. J.: S3-2 measurements of polar cap potential, J. Geophys. Res., 88, 9125, 1983.

Dungey, J. W.: Conditions for the occurrence of electrical discharges in astrophysical systems, Phil. Mag., 44, 725, 1953.

Dungey, J. W.: Interplanetary magnetic field and the auroral zones, Phys. Rev. Lett., 6, 47, 1961.

Eather, R. H.: Auroral proton precipitation and hydrogen emissions, Rev. Geophys., 5, 207, 1967.

Eather, R. H.: Polar cusp dynamics, J. Geophys. Res., 90, 1569_ $1576,1985$.

Etemadi, A., Cowley, S. W. H., Lockwood, M., Bromage, B. J. I., Willis, D. M., and Lühr, H.: The dependence of high-latitude dayside ionospheric flows on the north-south component of the IMF, a high time resolution correlation analysis using EISCAT "POLAR" and AMPTE UKS and IRM data, Planet. Space Sci.,
36, 471, 1988.

Fedder, J. A., Mobarry, C. M., and Lyon, J. G.: Reconnection voltage as a function of IMF clock angle, Geophys. Res. Lett., 18, 1047-1050, 1991

Fedorov, A., Budnik, E., Novrachev, M., Romanov, V., Song, P., and Savaud, J.-A.: Plasma characteristics near the exterior cusp under different orientations of the interplanetary magnetic field, Czech J. Phys., 49, 711-732, 1999.

Fedorov, A.: Characteristics of the exterior cusp for steady southward IMF, J. Geophys. Res., 105, 15 945, 2000.

Feldstein, Y. I. and Starkov, G. V.: Dynamics of the auroral belt and polar geomagnetic disturbances, Planet. Space Sci., 15, 209, 1967.

Freeman, M. P. and Southwood, D. J.: The effects of magnetospheric erosion on mid- and high-latitude ionospheric flows, Planet. Space Sci., 36, 509, 1988.

Frey, H. U., Mende, S. B., Carlson, C. W., Gérard, G.-C., Hubert, B., Spann, J., Gladstone, R., and Immel, T. J.: The electron and proton aurora seen by IMAGE-FUV and FAST, Geophys. Res. Lett., 28, 1135-1139, 2001.

Frey, H. U., Mende, S. B., Immel, T. J., Fuselier, S. A., Claflin, E. S., Gérarad, G.-C., and Hubert, B.: Proton aurora in the cusp, J. Geophys. Res., 10.1029, 2/1-2/17, July 2002.

Friis-Christensen, E., Kamide, Y., Richmond, A. D., and Matsushita, S.: Interplanetary magnetic field control of high-latitude electric fields and currents determined from Greenland magnetometer data, J. Geophys. Res., 90, 1325, 1985.

Fuselier, S. A., Klumpar, D. M., and Shelley, E. G.: Ion reflection and transmission during reconnection at the Earth's subsolar magnetopause, Geophys. Res. Lett., 18, 139-142, 1991.

Fuselier, S., Anderson, B. J., and Onsager, T. G.: Electron and ion signatures of field line topology at the low shear magnetopause, J. Geophys. Res., 100, 11 805-11 814, 1995.

Gérard, J.-C., Hubert, B., Meurant, M., Shematovich, V. I., Bisoikalo, D. V., Frey, H., Mende, S., and Gladstone, G. R.: Observations of the proton aurora with IMAGE FUV imager and simultaneous ion flux measurements, J. Geophys. Res., 106, 28 939-28 948, 2001

Gonzalez, W. D. and Mozer, F. S.: A quantitative model for the potential resulting from reconnection with an arbitrary interplanetary magnetic field, J. Geophys. Res., 79, 4186, 1974.

Gosling, J. T., Thomsen, M. F., Bame, S. J., Elphic, R. C., and Russell, C. T.: Plasma flow reversals at the dayside magnetopause and the origin of asymmetric polar cap convection, J. Geophys. Res., 95, 8073-8084. 1990a

Gosling, J. T., Thomsen, M. F., Bame, S. J., Elphic, R. C., and Russell, C. T.: Cold ion beams in the low-latitude boundary layer during accelerated flow events, Geophys. Res. Lett., 17, 22452248, 1990b.

Gosling, J. T., Thomsen, M. F., Bame, S. J., Elphic, R. C., and Russell, C. T.: Observations of reconnection of interplanetary and lobe magnetic field lines at the latitude magnetopause, J. Geophys. Res., 96, 14 097-14 106, 1991.

Greenwald, R. A., Baker, K. B., Ruohoniemi, J. M., Dudeney, J. R., Pinnock, N., Mattin, N., Leonard, J. M., and Lepping, R. P.: Simultaneous conjugate observations of dynamic variations in high-latitude dayside convection due to changes in IMF $B_{y}, \mathrm{~J}$ Geophys. Res., 95, 8057-8072, 1990.

Hill, T. W. and Reiff, P. H.: Evidence of magnetospheric cusp proton acceleration by magnetic merging at the dayside magnetopause, J. Geophys. Res., 82, 3623-3628, 1977.

Horwitz, J. L. and Akasofu, S.-I.: The response of the dayside 
aurora to sharp northward and southward transitions of the interplanetary magnetic field and to magnetospheric substorms, J. Geophys. Res., 82, 2723-2734, 1977.

Hubert, B., Gérard, J.-C., Bisoikalo, D. V., Shematovich, V. I., and Solomon, S. C.: The role of proton precipitation in the excitation of the auroral FUV emissions, J. Geophys. Res., 106, $21475-$ $21494,2001$.

Johnstone, A. D., Rodgers, D. J., Coates, A. J., Smith, M. F., and Southwood, D. J.: Ion acceleration during steady-state reconnection at the dayside magnetopause, in: Ion acceleration in the magnetosphere and ionosphere, (Ed) Chang, T., AGU Monograph 38, 136-145, 1986.

Kawano, H. and Russell, C. T.: Survey of flux transfer events observed with the ISEE spacecraft: rotational polarity and the source region, J. Geophys. Res., 101, 27 299-27 308, 1996.

Kawano, H. and Russell, C. T.: Survey of flux transfer events observed with the ISEE spacecraft: dependence on the interplanetary magnetic field, J. Geophys. Res., 102, 11 307-11 313, 1997.

Kim, K.-H., Lin, N., Cattell, C. A., Song, Y., and Lee, D.-H.: Evidence for component merging near the subsolar magnetopause: Geotail observations, Geophys. Res. Lett., 29, 10.1029, 4/1-4/3, 2002.

Kobel, E. and Flückiger, E. O.: A model of the steady-state magnetic field in the magnetosheath, J. Geophys. Res., 99, 23617, 1994.

Kremser, G., Woch, J., Mursula, K., Tanskanen, P., Wilken, B., and Lundin, R.: Origin of energetic ions in the polar cusp inferred from ion composition measurements by the Viking satellite, Ann. Geophysicae, 13, 595-607, 1995.

Leontyev, S. V., Starkov, G. V., Vorobjev, V. G., and Zverev, V. L.: Dayside aurorae and their relations to other geophysical phenomena, Planet. Space Sci., 40, 621-639, 1992.

Lockwood, M.: Ionospheric signatures of pulsed magnetopause reconnection, in: "Physical signatures of magnetopause boundary layer Processes", (Eds) Holtet, J. A. and Egeland, A., NATO ASI Ser., Ser. C, 425, 229-243, 1994.

Lockwood, M.: The location and characteristics of the reconnection X-line deduced from low-altitude satellite and ground-based observations: 1. Theory, J. Geophys. Res., 100, 21 791-21 802, 1995.

Lockwood, M.: The relationship of dayside auroral precipitations to the open-closed separatrix and the pattern of convective flow, J. Geophys. Res., 102, 17 475-17487, 1997a.

Lockwood, M.: Energy and pitch angle dispersions of LLBL/cusp ions seen at middle altitudes: predictions by the open magnetosphere model, Ann. Geophysicae, 15 , 1501-1514, $1997 \mathrm{~b}$.

Lockwood, M.: Identifying the open-closed field line boundary, in: "Polar Cap Boundary Phenomena ", (Eds) Moen, J., Egeland, A., and Lockwood, M., NATO ASI Series C, Vol. 509, pp 73-90, Kluwer, Dordrecht, 1998.

Lockwood, M.: A numerical model of the ionospheric signatures of time-varying magnetic reconnection: I. Ionospheric convection, Ann. Geophysicae, submitted, 2002.

Lockwood, M. and Cowley, S. W. H.: Comment on "A statistical study of the ionospheric convection response to changing interplanetary magnetic field conditions using the assimilative mapping of ionospheric electrodynamics technique", J. Geophys. Res., 104, 4390-4392, 1999.

Lockwood, M. and Davis, C. J.: On the longitudinal extent of magnetopause reconnection bursts, Ann. Geophysicae, 14, 865-878, 1996.

Lockwood, M. and Moen, J.: Ion populations on open field lines within the low-latitude boundary layer: theory and observations during a dayside transient event, Geophys. Res. Lett., 23, 2895 2898, 1996.

Lockwood, M. and Moen, J.: Reconfiguration and closure of lobe flux by reconnection during northward IMF: evidence for signatures in cusp/cleft auroral emissions, Ann. Geophysicae, 17, 996-1011, 1999.

Lockwood, M., van Eyken, A. P., Bromage, B. J. I., Willis, D. M., and Cowley, S. W. H.: Eastward propagation of a plasma convection enhancement following a southward turning of the interplanetary magnetic field, Geophys. Res. Lett., 13, 72-75, 1986.

Lockwood, M., Cowley, S. W. H., and Freeman, M. P.: The excitation of plasma convection in the high latitude ionosphere, J. Geophys Res., 95, 7961-7971, 1990.

Lockwood, M., Moen, J., Cowley, S. W. H., Farmer, A. D., Løvhaug, U. P., Lühr, H., and Davda, V. N.: Variability of dayside convection and motions of the cusp/cleft aurora, Geophys. Res. Lett., 20, 1011-1014, 1993.

Lockwood, M., Onsager, T. G., Davis, C. J., Smith, M. F., and Denig, W. F: The characteristics of the magnetopause reconnection X-line deduced from low-altitude satellite observations of cusp ions, Geophys. Res. Lett., 21, 2757-2760, 1994.

Lockwood, M., Davis, C. J., Smith, M. F., Onsager, T. G., and Denig, W. F: The location and characteristics of the reconnection $\mathrm{X}$-line deduced from low-altitude satellite and ground-based observations: 2. DMSP and EISCAT radar data, J. Geophys. Res., 100, 21 803-21 814, 1995.

Lockwood, M., Cowley, S. W. H., and Onsager, T. G.: Ion acceleration at both the interior and exterior Alfvén waves associated with the magnetopause reconnection site: signatures in cusp precipitation, J. Geophys. Res., 101, 21 501-21 515, 1996.

Lockwood, M., Davis, C. J., Onsager, T. G., and Scudder, J. A.: Modelling signatures of pulsed magnetopause reconnection in cusp ion dispersion signatures seen at middle altitudes, Geophys. Res. Lett., 25, 591-594, 1998.

Lockwood, M., Wild, M. N., and Cowley, S. W. H.: The Onset and Expansion of Enhanced Ionospheric Convection Following a Southward Turning of the IMF, RAL Repot, 1999.

Lorentzen, D. A. and Moen, J.: Auroral proton and electron signatures in the dayside aurora, J. Geophys. Res., 105, 12733 $12745,2000$.

Luhmann, J. G., Walker, R. J., Russell, C. T., Crooker, N. U., Spreiter, J. R., and Stahara, S. S.: Patterns of potential magnetic field merging sites on the dayside magnetopause, J. Geophys. Res., 89, 1739, 1984.

Lummerzheim, D., Galand, M., Semeter, J., Mendillo, M. J., Rees, M. H., and Rich, F. J.: Emission of OI(630 nm) in proton aurora, J. Geophys. Res., 106, 141-148, 2001.

Maezawa, K.: Dependence of the magnetopause position on the southward interplanetary magnetic field, Planet. Space Sci., 22, 1443, 1974.

McCrea, I. W, Lockwood, M., Moen, J., Pitout, F., Eglitis, P., Aylward, A. D., Cerisier, J.-C., Thorolfsson, A., and Milan, S. E.: ESR and EISCAT observations of the response of the cusp and cleft to IMF orientation changes, Ann. Geophysicae, 18, 10091026, 2000.

McWilliams, K. A., Milan, S. E., Yeoman, T. K., Sigwarth, J. B., Frank, L. A., and Brittnacher, M.: IMF $B_{y}$ dependence of the relative position of the dayside ultraviolet auroral oval and the HF radar cusp, J. Geophys. Res., in press, 2001.

Mende, S. B., Heetderks, H., and Frey, H. U.: Far ultraviolet imaging from the IMAGE spacecraft, 1. System design, Space Sci. 
Rev., 91, 287, 2000a.

Mende, S. B., Heetderks, H., and Frey, H. U.: Far ultraviolet imaging from the IMAGE spacecraft, 3. Spectral imaging of Lyman alpha and OI $135.6 \mathrm{~nm}$, Space Sci. Rev., 91, 287, $2000 \mathrm{~b}$.

Milan, S. E., Lester, M., Cowley, S. W. H., and Brittnacher, M.: Convection and auroral response to a southward turning of the IMF: Polar UVI, CUTLASS and IMAGE signatures of transient magnetic flux transfer at the magnetopause, J. Geophys. Res., 105, 15 741-15 755, 2000a.

Milan, S. E., Lester, M., Cowley, S. W. H., and Brittnacher, M.: Dayside convection and auroral morphology during an interval of northward interplanetary magnetic field, Ann. Geophysicae, $18,436-444,2000 b$.

Moen, J., Lorentzen, D. A., and Sigernes, F.: Dayside moving auroral forms and bursty proton auroral events in relation to particle boundaries observed by NOAA-12, J. Geophys. Res., 103, 14 855-14 863, 1998.

Moen, J., Carlson, H. C., and Sandholt, P. E.: Continuous observations of cusp auroral dynamics in response to an IMF $B_{Y}$ polarity change, Geophys. Res. Lett., 26, 1243-1246, 1999.

Newell, P. T. and Meng, C.-I.: Mapping the dayside ionosphere to the magnetosphere according to particle precipitation characteristics, Geophys. Res. Lett., 19, 609-612, 1992.

Nishida, A.: Coherence of geomagnetic DP2 fluctuations with interplanetary magnetic field variations, J. Geophys. Res., 73, 5549, 1968a.

Nishida, A.: Geomagnetic DP 2 fluctuations and associated magnetospheric phenomena, J. Geophys. Res., 73, 1795, 1968b.

Nishitani, N., Ogawa, T., Sato, N., Yamagishi, H., Pinnock, M., Villain, J.-P., Sofko, G., and Troschichev, O.: A study of the dusk cell's response to an IMF southward turning, J. Geophys. Res., 107, 10.1029, 3/1-3/15, 2002.

Onsager, T. G., Kletzing, C. A., Austin, J. B., and MacKiernan, H.: Model of magnetosheath plasma in the magnetosphere: cusp and mantle precipitations at low altitudes, Geophys. Res. Lett., 20, 479-482, 1993.

Onsager, T. G. and Fuselier, S. A.: The location of the magnetopause reconnection for northward and southward interplanetary magnetic field, in: Solar System Plasmas in Space and Time, Geophys. Mono. Ser., vol. 84, (Eds) Burch, J. L. and Waite, Jr, J. H., pp. 183-197, AGU, Washington D. C., 1994.

Onsager, T. G., Scudder, J. D., Lockwood, M., and Russell, C. T.: Reconnection at the High-Latitude Magnetopause During Northward IMF Conditions, J. Geophys. Res., 106, 25 467-25 488, 2001.

Opgenoorth, H. J., Lockwood, M., Alcaydé, D., Donovan, E., Engebretson, M. J., van Eyken, A. P., Kauristie, K., Lester, M., Moen, J., Waterman, J., Alleyne, H., Andre, M., Dunlop, M. W., Cornilleau-Wehrlin, N., Decreau, P. M. E., Fazerkerley, A., Reme, H., Andre, R., Amm, O., Balogh, A., Behlke, R., Blelly, P. L., Boholm, H., Borälv, E., Bosqued, J. M., Buchert, S., Candidi, M., Cerisier, J. C., Cully, C., Denig, W. F., Doe, R., Eglitis, P., Greenwald, R. A., Jackal, B., Kelly, J. D., Krauklis, I., Lu, G., Mann, I. R., Marcucci, M. F., McCrea, I. W., Maksimovic, M., Massetti, S., Masson, A., Milling, D. K., Orsini, S., Pitout, F., Provan, G., Ruohoniemi, J. M., Samson, J. C, Schott, J. J., Sedgemore-Schulthess, F., Stamper, R., Stauning, P., Strömme, A., Taylor, M., Vaivads, A., Villain, J. P., Voronkov, I., Wild, J., and Wild, M.: Coordinated Ground-Based, Low Altitude Satellite and Cluster Observations on Global and Local Scales During a Transient Postnoon Sector Excursion of the Magnetospheric Cusp, Ann. Geophysicae, 19, 1367-1398, 2001.
Paschmann, G., Sonnerup, B. U. Ö., Papamastorakis, I., Sckopke, N., Haerendel, G., Bame, S. J., Ashbridge, J. R., Gosling, J. T., Russell, C. T., and Elphic, R. C.: Plasma acceleration at the Earth's magnetopause: Evidence for reconnection, Nature, 282, 243-246, 1979.

Paschmann, G., Papamastorakis, I., Baumjohann, W., Sckopke, N., Carlson, C. W., Sonnerup, B. U. Ö., and Lühr, H.: The magnetopause for large magnetic shear: AMPTE/IRM observations, J. Geophys. Res., 91, 11 099-11 115, 1986.

Paschmann, G., Sonnerup, B., Papamastorakis, I., Baumjohann, W., Sckopke, N., and Lühr, H.: The magnetopause and boundary layer for small magnetic shear: Convection electric fields and reconnection, Geophys. Res. Lett., 17, 1829-1832, 1990.

Petrinec, S. M. and Russell, C. T.: External and internal influences on the size of the dayside terrestrial magnetosphere, Geophys. Res. Lett., 20, 339-342, 1993.

Reiff, P. H. and Luhmann, J. G.: Solar wind control of the polar cap voltage, in: "Solar Wind-Magnetosphere Coupling", (Eds) Kamide, Y. and Slavin, J. A., p. 453, Terra Scientifica, Tokyo, 1986.

Reiff, P. H., Hill, T. W., and Burch, J. L.: Solar wind plasma injection at the dayside magnetospheric cusp, J. Geophys. Res., 82, 479-491, 1977.

Reiff, P. H., Burch, J. L., and Spiro, R. W.: Cusp proton signatures and the interplanetary magnetic field, J. Geophys. Res., 85, 5997, 1980.

Reiff, P. H., Spiro, R. W., and Hill, T. W.: Dependence of polar cap potential drop on interplanetary parameters, J. Geophys. Res., 86, 7639, 1981.

Ridley, A. J., Lu, G., Clauer, C. R., and Papitashvilli, V. O.: A statistical study of the ionospheric convection response to changing interplanetary magnetic field conditions using the assimilative mapping of ionospheric electrodynamics technique, J. Geophys. Res., 103, 4023-4039, 1998.

Rishbeth, H., Smith, P. R., Cowley, S. W. H., Willis, D. M., van Eyken, A. P., Bromage, B. J. I., and Crothers, S. R.: Ionospheric response to changes in the interplanetary magnetic field observed by EISCAT and AMPTE-UKS, Nature, 318, 451-452, 1985.

Ruohoniemi, J. M. and Greenwald, R. A.: The response of high latitude convection to a sudden southward IMF turning, Geophys. Res. Lett., 25, 2913-2916, 1998.

Ruohoniemi, J. M. and Baker, K. L.: Large-scale imaging of highlatitude convection with Super Dual Auroral Radar Network HF radar observation, J. Geophys. Res., 103, $20797,1998$.

Rijnbeek, R. P., Cowley, S. W. H., Southwood, D. J., and Russell, C. T.: A survey of dayside flux transfer events observed by the ISEE 1 and 2 magnetometers, J. Geophys. Res., 89, 786-800, 1984.

Roelof, E. C. and Sibeck, D. G.: Magnetopause shape as a bivariate function of interplanetary magnetic field $B_{z}$ and solar wind dynamic pressure, J. Geophys. Res., 98, 21 421-21 450, 1993.

Russell, C. T., Berchem, J., and Luhmann, J.: On the source region of flux transfer events, Adv. in Space Res., 5, 363, 1985.

Šafránková, J., Němeček, Z., Sibeck, D. G. H., Přech, L., Merka, J., and Santolík, O.: Two point observation of high-latitude reconnection, Geophys. Res. Lett., 25, 4301, 1998.

Sandholt, P. E.: IMF control of the polar cusp and cleft auroras, Adv. in Space Res., 8, (9), 21-34, 1988.

Sandholt, P. E., Farrugia, C. J., Moen, J., and Lybekk, B.: The dayside aurora and its regulation by the interplanetary magnetic field, in: "Polar Cap Boundary Phenomena ", (Eds) Moen, J., Egeland, A., and Lockwood, M., NATO ASI Series C, Vol. 509, pp. 189-208, Kluwer, Dordrecht, 1998. 
Saunders, M. A., Freeman, M. P., Southwood, D. J., Cowley, S. W. H., Lockwood, M., Samson, J. C., Farrugia, C. J., and Hughes, T. J.: Dayside ionospheric convection changes in response to long period IMF oscillations: determination of the ionospheric phase velocity, J. Geophys. Res., 97, 19373-19380, 1992.

Savin, S.: Turbulent boundary layeray the border of the geomagnetic trap, J.E.T.P. Letters, 84(11) 545-551, 2001.

Schatten, K. H. and Wilcox, J. W.: Response of geomagnetic activity index $K_{p}$ to interplanetary magnetic field, J. Geophys. Res., 72, 5185, 1967.

Scurry, L., Russell, C. T., and Gosling, J. T.: A statistical study of accelerated flow events at the dayside magnetopause, J. Geophys. Res., 99, 14 815-14 829, 1994.

Siscoe, G. L. and Huang, T. S.: Polar cap inflation and deflation, J. Geophys. Res., 90, 543, 1985.

Smith, M. F. and Rodgers, D. J.: Ion distributions at the dayside magnetopause, J. Geophys. Res., 95, 11 617-11 624, 1991.

Song, P. and Russell, C. T.: Model of the formation of the lowlatitude boundary layer for strongly northward interplanetary magnetic field, J. Geophys. Res., 97, 1411-1420, 1992.

Song, P., Holzer, T. E., Russell, C. T., and Wang, Z.: Modelling the low-latitude boundary layer with reconnection entry, Geophys. Res. Lett. 21, 625-628, 1994.

Sonnerup, B. U. Ö.: Magnetopause reconnection rate, J. Geophys. Res., 79, 1546, 1974.

Sonnerup, B. U. Ö., Paschmann, G., Papamastorakis, I., Sckopke, N., Haerendel, G., Bame, S. J., Ashbridge, J. R., Gosling, J. T., and Russell, C. T.: Evidence for magnetic field reconnection at the Earth's magnetopause, J. Geophys. Res., 86, 10 049-10 067, 1981.

Sonnerup, B. U. Ö., Papamastorakis, I., Paschmann, G., and Lühr, H.: The magnetopause for large magnetic shear: analysis of convection electric fields from AMPTE/IRM, J. Geophys. Res., 95, 10 541-10 557, 1986.
Sonnerup, B. U. Ö., Paschmann, G., Papamastorakis, I., Sckopke, N., Haerendel, G., Bame, S. J., Ashbridge, J. R., Gosling, J. T., and Russell, C. T.: Evidence for magnetic field reconnection at the Earth's magnetopause, J. Geophys. Res., 86, 10 049-10067, 1990.

Spreiter, J. R., Summers, A. L., and Alksne, A. Y.: Hydromagnetic flow around the magnetosphere, Planet. Space Sci., 14, 223-253, 1966.

Strickland, D. J., Daniell, R. E., Jasperse, J. R., and Basu, B.: Transport-theoretic model for the electron-proton-hydrogen atom aurora 2. Model results, J. Geophys. Res., 98, 21533 $21548,1993$.

Stubbs, T. J., Lockwood, M., Cargill, P., Fennel, J., Grande, M., Kellett, B., Perry C. H., and Rees, A.: Dawn/dusk asymmetry in particles of solar wind origin within the magnetosphere, Ann. Geophysicae, 19, 1-9, 2001.

Todd, H., Cowley, S. W. H., Lockwood, M., Willis, D. M., and Lühr, H.: Response time of the high-latitude dayside ionosphere to sudden changes in the north-south component of the IMF, Planet. Space Sci., 36, 1415-1428, 1988.

Topliss, S. M., Owen, C. J., and Peterson, W.: A Simple Model of Complex Cusp Ion Dispersions During Intervals of Northward Interplanetary Magnetic Field, Geophys. Res. Lett., 27, 35873590, 2000.

Vorobjev, V. G., Gustafsson, G., Starkov, G. V., Feldstein, Y. I., and Shevnina, N. F.: Dynamics of day and night aurora during substorms, Planet Space Sci., 23, 269, 1975.

Weiss, L. A., Reiff, P. H., Weber, E. J., Carlson, H. C., Lockwood, M., and Peterson, W. K.: Flow-aligned jets in the magnetospheric cusp: results from the Geospace Environment Modelling pilot programme, J. Geophys. Res., 100, 7649-7660, 1995.

Woch, J. and Lundin, R.: Magnetosheath plasma precipitation in the polar cusp and its control by the interplanetary magnetic field, J. Geophys. Res., 97, 1421-1430, 1992. 